\title{
Web Crippling Behaviour of Cold-Formed Duplex Stainless Steel \\ Tubular Sections at Elevated Temperatures
}

\author{
Feng Zhou $^{1}$ \& Ben Young ${ }^{2}$ \\ ${ }^{1}$ Department of Building Engineering, Tongji University, 1239 Siping Road, Shanghai 200092, China \\ ${ }^{2}$ Department of Civil Engineering, The University of Hong Kong, Pokfulam Road, Hong Kong, China
}

Abstract: This paper reports a numerical investigation of cold-formed high strength stainless steel square and rectangular hollow sections subjected to web crippling at elevated temperatures. Finite element analysis was conducted on cold-formed high strength austenitic and duplex stainless steel material. Four loading conditions specified in the American Specification and Australian/New Zealand Standard for cold-formed stainless steel structures were investigated in the numerical study. A non-linear finite element model which includes geometric and material non-linearities was developed and verified against experimental results. It was shown that the finite element model closely predicted the web crippling strengths and failure modes of the tested specimens under the four loading conditions. Hence, parametric study was carried out to investigate the web crippling behaviour of cold-formed high strength stainless steel square and rectangular hollow sections at elevated temperatures. The web crippling strengths predicted from the finite element analysis were compared with the design strengths obtained using the American, Australian/New Zealand and European specifications for stainless steel structures by substituting the reduced material properties in the current web crippling design equations. A unified web crippling equation for cold-formed high strength stainless steel square and rectangular hollow sections at elevated temperatures is proposed. It is demonstrated that the web crippling strength obtained using the proposed equation is safe and reliable using reliability analysis.

Keywords: Cold-formed steel; Elevated temperatures; Finite element analysis; Proposed design equation; Stainless steel; Tubular sections; Web crippling.

\footnotetext{
*Corresponding author. Tel.: +852 2859 2674; fax: +852 25595337

E-mail address: young@hku.hk (B. Young)
} 


\section{Introduction}

Stainless steels are used in building applications for structural and decorative purpose. For examples, the St Paul's Cathedral in London and the roof of Chrysler Building in New York. Stainless steel does not only have decorative functions, but it can also provide more durable buildings, better fire resistance and better corrosion resistance. Hence, stainless steel has been increasingly used in structural applications in recent years. Significant progress has been made in recent years in the development of design guidance for stainless steel structures in ambient temperature (room temperature). However, investigation of the structural performance of stainless steel structural members at elevated temperatures is relatively limited [1 - 4].

It is recognized that stainless steel has better structural performance in terms of stiffness and strength than carbon steel at elevated temperatures. Material behaviour of cold-formed stainless steel at elevated temperatures has been reported by Chen and Young [1]. Tensile coupon tests were conducted at different temperatures ranged from approximately 20 to $1000^{\circ} \mathrm{C}$ under both steady and transient state tests. The material properties of stainless steel types EN 1.4462 (Duplex) and EN 1.4301 (AISI 304) were obtained. A unified equation with different coefficients for yield strength, elastic modulus, ultimate strength and ultimate strain of stainless steel at elevated temperatures was proposed based on the test data. The material properties of stainless steel at elevated temperatures have also been conducted [5 - 8]. The findings of these investigations demonstrated the superior material properties of stainless steel at elevated temperatures, particularly in the temperature ranged approximately from $500-800^{\circ} \mathrm{C}$. For example, generally at $800^{\circ} \mathrm{C}$ the strength retention of stainless steel is almost 4 times higher than those of carbon steel, and the stiffness retention is 7 times higher than those of carbon steel.

Web crippling is a form of localised buckling that occurs at points of concentrated loads or supports of structural members. Cold-formed stainless steel members that are unstiffened against this type of loading could cause structural failure by web crippling. Cold-formed stainless steel 
members subjected to web crippling have two different type failure modes. They are web buckling, where the web crippling capacity mainly depends on the stiffness of the material, and web yielding, where the web crippling capacity mainly depends on the yield strength of the material. The current web crippling design rules in most of the specifications for cold-formed stainless steel structures are generally empirical in nature and are based on the test results of coldformed carbon steel. Furthermore, no web crippling design rules are given for stainless steel members at elevated temperatures. Hence, in this study, the web crippling design rules in the current American [9], Australian/New Zealand [10] and European [11] specifications for coldformed stainless steel square and rectangular hollow sections are examined for the possibility of using the design rules at elevated temperatures. In doing so, the reduced material properties at elevated temperatures are used in calculating the web crippling strengths.

The objectives of this paper are to numerically investigate the behaviour of cold-formed high strength stainless steel square and rectangular hollow sections subjected to web crippling at elevated temperatures. The finite element analysis (FEA) program ABAQUS [12] was used for the numerical investigation. An accurate finite element model (FEM) that includes geometric and material nonlinearities was developed and verified against the web crippling tests conducted by Zhou and Young [13] at room temperature. Parametric study was carried out to study the structural performance of cold-formed stainless steel square and rectangular hollow sections subjected to web crippling at elevated temperatures. The stress-strain curves of cold-formed stainless steel tubular sections at elevated temperatures measured by Chen and Young [1] were used in the parametric study. The web crippling design rules in the current specifications [9-11] for cold-formed stainless steel square and rectangular hollow sections at elevated temperatures is assessed by comparing the web crippling strengths predicted from the finite element analysis. The reduced material properties were used to calculate the web crippling strengths. In addition, the NAS Specification [14] for cold-formed carbon steel structural members was also used to predict 
the design strengths. Furthermore, a unified web crippling equation is proposed for cold-formed high strength stainless steel tubular sections subjected to web crippling at elevated temperatures by considering the reduced yield strength and stiffness at elevated temperatures.

\section{Summary of experimental investigation}

The experimental investigation of cold-formed high strength stainless steel tubular sections subjected to web crippling was performed at room temperature by Zhou and Young [13]. The duplex and high strength austenitic stainless steel square hollow sections (SHS) and rectangular hollow sections (RHS) that included four SHS (Series SHS1, SHS2, SHS3 and SH4) and three RHS (Series RHS1, RHS2 and RHS3) were investigated. The nominal section sizes ( $d \times$ $b_{f} \times t$ ) were $40 \times 40 \times 2,50 \times 50 \times 1.5,150 \times 150 \times 3,150 \times 150 \times 6,140 \times 80 \times 3,160 \times 80 \times 3$ and $200 \times 110 \times 4$ for Series SHS1, SHS2, SHS3, SHS4, RHS1, RHS2 and RHS3, respectively, where $d$ is the overall depth of web, $b_{f}$ is the overall width of flange and $t$ is the web thickness in millimeters as shown in Fig. 1(a). The measured cross-section dimensions of the test specimens are detailed in Zhou and Young [13].

The material properties of the flat portion of the specimens for each series were determined by tensile coupon tests. The coupons were taken from the center of the face at $90^{\circ}$ angle from the weld in the longitudinal direction of the untested specimens. The tensile coupons were prepared and tested according to the American Society for Testing and Materials Standard [15] and the Australian Standard AS 1391 [16] for the tensile testing of metals using $12.5 \mathrm{~mm}$

wide coupons of gauge length $50 \mathrm{~mm}$. The measured Young's modulus $(E)$, static $0.2 \%$ proof stress $\left(\sigma_{0.2}\right)$ and ultimate tensile strength $\left(\sigma_{u}\right)$ as well as the elongation after fracture $\left(\varepsilon_{f}\right)$ for Series SHS1, SHS2, SHS3, SHS4, RHS1, RHS2 and RHS3 are shown in Table 1. The material properties of the corner portion of the specimens were also determined by tensile coupon tests for Series RHS2 and RHS3. The material properties of the corners for specimens in Series SHS1, 
SHS2, SHS3, SHS4 and RHS1 were extrapolated from Series RHS2 according to the measured $\sigma_{0.2}, \sigma_{u}$ and $\varepsilon_{f}$ in the flat and corner portions. The tensile coupon tests of the flat and corner portions are detailed in Young and Lui [17].

The tests were conducted under four loading conditions as specified in the ASCE Specification [9] and AS/NZS Standard [10] for cold-formed stainless steel structures, namely end-one-flange (EOF), interior-one-flange (IOF), end-two-flange (ETF) and interior-two-flange (ITF) loading conditions. A servo-controlled hydraulic testing machine was used to apply a concentrated compressive force to the test specimens. Displacement control was used to drive the hydraulic actuator at a constant speed of $0.3 \mathrm{~mm} / \mathrm{min}$ for all test specimens. The load or reaction forces were applied by means of bearing plates. The web crippling tests are detailed in Zhou and Young [13].

\section{Finite element model}

\subsection{General}

The finite element program ABAQUS [12] was used to simulate the cold-formed high strength stainless steel tubular sections subjected to web crippling. There are three main components that need to be modelled. These components are the bearing plates, the stainless steel section and the interfaces between the bearing plates and the stainless steel section. In the finite element model (FEM), the measured cross-section dimensions and material properties obtained from the tests were used. The model was based on the centreline dimensions of the cross-sections. The corners of the cold-formed stainless steel sections were accurately modelled.

\subsection{Element Type and Mesh}

The bearing plates were modelled using analytical rigid plates, and the cold-formed high strength stainless steel section was modelled using the S4R shell element. It is mentioned in the 
ABAQUS manual that S4R element which is a four-node doubly curved thin or thick shell element with reduced integration is suitable for complex buckling behaviour. The S4R element has six degrees of freedom per node and provides accurate solutions to most applications [12]. The finite element mesh used in the model was investigated by varying the size of the elements in the cross-section to provide both accurate results and less computational time. The finite element mesh sizes ranged from $2 \times 2 \mathrm{~mm}$ (length by width) to $10 \times 10 \mathrm{~mm}$ were used for the flanges and webs depending on the size of the sections, where a finer mesh size of 6 elements at the corners of the sections was used. The typical finite element mesh of the square and rectangular hollow sections under the end and interior loading conditions are shown in Figures $2-5$.

\subsection{Boundary Condition and Interface}

Due to symmetry, only one-half of the cross-section was modelled, as shown in Fig. 1(b). The nodes on symmetry surface were prevented from translational displacement in the $\mathrm{X}$ direction and rotation about the $\mathrm{Y}$ and $\mathrm{Z}$ axes, as shown in Figures $2-5$. The interfaces between the bearing plates and the cold-formed high strength stainless steel section are modelled using the contact pairs. The contact pair allows the surfaces to separate under the influence of a tensile force. However, the two contact surfaces are not allowed to penetrate each other.

\subsection{Method of Loading}

The loading method used in the finite element analysis was identical to that used in the tests. The displacement control method was used for the analysis of the cold-formed high strength stainless steel square and rectangular hollow sections subjected to web crippling. Transverse compressive load was applied to the specimen by specifying a displacement to the reference point of the analytical rigid plate that modelled the bearing plate. 


\subsection{Material Modelling}

The measured stress-strain curves of the specimens at room and elevated temperatures were used in the analysis. The material behaviour provided by ABAQUS allows for the multilinear stress-strain curve to be used. The first part of the multi-linear curve represents the elastic part up to the proportional limit stress with measured Young’s modulus and Poisson's ratio equal to 0.3. Since the analysis of post-buckling involves large in-elastic strains, the nominal (engineering) static stress-strain curve was converted to a true stress and logarithmic plastic strain curve. The true stress $\left(\sigma_{\text {true }}\right)$ and plastic true strain $\left(\varepsilon_{\text {true }}^{p l}\right)$ are specified in ABAQUS [12].

\section{Verification of finite element model}

In the verification of the finite element model (FEM), a total of 28 cold-formed high strength stainless steel tubular sections subjected to web crippling tested by Zhou and Young [13] at room temperature were analysed in this study. The measured cross-section dimensions and stress-strain curves for flat portions of the specimens were used in the analysis. In addition, the measured and predicted stress-strain curves of the corner portions of the specimens were also used. A comparison between the experimental results $\left(P_{E x p}\right)$ and the finite element results $\left(P_{F E A}\right)$ was carried out to verify the accuracy of the finite element model, as shown in Table 2. Generally, it can be seen that good agreement has been achieved between both results for all specimens. A maximum difference of $9 \%$ was observed between the experimental and numerical results for specimens EOF160×80×3N75, IOF50×50×1.5N50, IOF150×150×3N75 and ETF160×80×3N75. The mean value of the $P_{E x p} / P_{F E A}$ ratio is 0.99 with the corresponding coefficient of variation (COV) of 0.061 .

Different failure modes were observed from the tests and verified by the finite element model for the four loading conditions, as shown in Figures $2-5$. It is shown that both the failure 
modes and the ultimate web crippling strengths reflect good agreement between the experimental and finite element results.

\section{Parametric study}

It is shown that the FEM can closely predict the behaviour of cold-formed high strength stainless steel square and rectangular hollow sections subjected to web crippling. Hence, parametric study was carried out to study the structural performance of cold-formed high strength stainless steel square and rectangular hollow sections subjected to web crippling at elevated temperatures. A total of 120 specimens for various temperatures were analyzed in the parametric study, and these temperatures are 22, 180, 450, 550, 760 and $960{ }^{\circ} \mathrm{C}$. The specimens consisted of five different section sizes, having the thicknesses $(t)$ ranged from 2 to $12 \mathrm{~mm}$, the overall depth of web $(d)$ is $200 \mathrm{~mm}$, and the flange width $\left(b_{f}\right)$ is $200 \mathrm{~mm}$. The sections are $200 \times 200 \times 2$, $200 \times 200 \times 3,200 \times 200 \times 4,200 \times 200 \times 8$ and $200 \times 200 \times 12$. The web slenderness $(h / t)$ value ranged from 13.7 to 87.0. The inside corner radius $\left(r_{i}\right)$ ranged from 6.0 to $11.0 \mathrm{~mm}$. A constant bearing length $(N)$ of $200 \mathrm{~mm}$ was used in all four loading conditions. The cross-section dimensions and web crippling strengths $\left(P_{F E A}\right)$ per web predicted from the FEA are summarized in Table 3 . The stress-strain curve of the flat portions of cold-formed duplex stainless steel tubular sections at elevated temperatures measured by Chen and Young [1] were used in the parametric study. The stress-strain curves of the corner regions of the cold-formed stainless steel section differ from those of the flat regions due to cold-working. It has been observed that enhancements in $0.2 \%$ proof strengths are obvious in the corners of roll-formed sections [18] at room temperature, but corner and flat material display similar proof strengths at high temperatures [7]. The enhancements of the corner regions have little effects on the ultimate web crippling capacity, due to the failure takes place in the web. Hence, the enhancements in $0.2 \%$ proof strengths of the corner regions are not considered in the parametric study. The measured material properties of 
yield stress $\left(\sigma_{0.2}\right)$ and elastic modulus $(E)$ for cold-formed high strength stainless steel at elevated temperatures are shown in Table 3.

The numerical results of the parametric study for the four loading conditions are shown in Table 4. The ultimate web crippling capacity decreases as the temperature increases. The loadweb deformation curves for Section $200 \times 200 \times 2$ under ETF loading condition at different temperatures are shown in Fig. 6. The vertical axis of the graph plotted the web crippling load per web and the horizontal axis plotted the web deformation in the direction of the applied load, which is the flange indentation of the hollow section. The reduction factors of ultimate web crippling capacity of cold-formed high strength stainless steel tubular sections under the four loading conditions at elevated temperatures as well as the material properties of yield stress $\left(\sigma_{0.2}\right)$ and elastic modulus $(E)$ are shown in Table 4. The comparison of the reduction factors of web crippling strengths under ETF loading condition with the measured material properties of yield stress $\left(\sigma_{0.2}\right)$ and elastic modulus $(E)$ is shown in Fig. 7. It is shown that the tubular sections with different web slenderness have a very similar of reduction in web crippling strength as the temperature increases. Furthermore, the reduction of yield stress is slightly lower than the web crippling strengths.

\section{Reliability analysis}

The reliability of the web crippling design rules is evaluated using reliability analysis. The reliability index $(\beta)$ is a relative measure of the safety of the design. A target reliability index of 3.0 for stainless steel structural members is recommended as a lower limit in the ASCE Specification [9]. The design rules are considered to be reliable if the reliability index is greater than or equal to 3.0. The resistance factor $\left(\phi_{w 1}\right)$ for web crippling strength as recommended by the current ASCE Specification [9], EC3 Code [11], and NAS Specification [14] for different loading conditions are shown in Tables $5-8$. The load combinations of 1.2DL + 1.6LL and 1.35DL + 
1.5LL as specified in the American Society of Civil Engineers Standard [19] and the European Code, respectively, were used in the reliability analysis, where DL is the dead load and LL is the live load. The statistical parameters are obtained from Table F1 of the NAS Specification for web crippling strength, where $M_{m}=1.10, F_{m}=1.00, V_{M}=0.10$, and $V_{F}=0.05$, which are the mean values and coefficients of variation for material properties and fabrication factors. The statistical parameters $P_{m}$ and $V_{P}$ are the mean value and coefficient of variation of load ratio, respectively, as shown in Tables 5-8. In calculating the reliability index, the correction factor in the NAS Specification was used. The respective resistance factor $\left(\phi_{w 1}\right)$ and load combinations for the current ASCE Specification, EC3 Code and NAS Specification were used to calculate the corresponding reliability index $\left(\beta_{1}\right)$. For the purpose of direct comparison, a constant resistance factor $\left(\phi_{w 2}\right)$ of 0.7 and a load combination of $1.2 \mathrm{DL}+1.6 \mathrm{LL}$ as specified in the ASCE Specification were used to calculate the reliability index $\left(\beta_{2}\right)$ for the EC3 Code and NAS Specification, as shown in Tables 5-8. Reliability analysis is detailed in the Commentaries of the ASCE Specification [20] and NAS Specification [21].

\section{Comparison of numerical results with current design strengths at elevated temperatures}

The web crippling strengths $\left(P_{F E A}\right)$ per web predicted from the finite element analysis at elevated temperatures were compared with the nominal web crippling strengths obtained using the ASCE Specification [9], AS/NZS Standard [10] and EC3 Code [11] Part 1.4 by substituting the reduced yield strength $\left(\sigma_{0.2}\right)$ and elastic modulus into the conventional design rules. The nominal web crippling strengths of the cold-formed high strength stainless steel tubular sections at elevated temperatures were calculated using the cross-section dimensions and the reduced material properties as shown in Table 3. The AS/NZS Standard [10] has adopted the web crippling design rules from the ASCE Specification [9]. Hence, the web crippling design strengths predicted by the ASCE Specification and the AS/NZS Standard are identical. The web crippling 
design rules in the EC3 Code [11] Part 1.4: Supplementary rules for stainless steel refers to the web crippling design rules of either the hot-rolled carbon steel in EC3 Code [22] Part 1.1 or the cold-formed carbon steel in EC3 Code [23] Part 1.3. In this paper, the EC3 Code [23] Part 1.3 was used to predict the web crippling strengths, this is because the test specimens were cold-formed. In addition, the web crippling strengths $\left(P_{F E A}\right)$ predicted from the FEA were also compared with the nominal web crippling strengths $\left(P_{N A S}\right)$ predicted using the NAS Specification [14] for coldformed carbon steel structural members. Tables 5-8 show the comparison of the web crippling strengths $\left(P_{F E A}\right)$ with the nominal (unfactored design) strengths at elevated temperatures for the four loading conditions (EOF, IOF, ETF and ITF).

In Tables 5-8, the design strengths predicted by the ASCE Specification and AS/NZS Standard are generally conservative and reliable for the EOF and ETF loading conditions, but unreliable for IOF and ITF loading conditions. The mean values of the load ratio $P_{F E A} / P_{A S C E}$ are 1.18 and 0.91 with the corresponding coefficients of variation (COV) of 0.247 and 0.271 , and the reliability indices $\left(\beta_{1}\right)$ of 2.94 and 2.09 for IOF and ITF loading conditions, respectively, as shown in Tables 6 and 8. For EC3 Code, the design strengths are generally very conservative and reliable for the four loading conditions at elevated temperatures. The maximum mean value of the load ratio $P_{F E A} / P_{E C 3}$ is 5.86 with the corresponding COV of 0.093 and the value of $\beta_{1}=9.10$ and $\beta_{2}=10.11$ for ITF loading condition, as shown in Table 8. For NAS Specification, the design strengths are generally conservative but unreliable, except for the EOF loading condition. The minimum mean value of the load ratio $P_{F E A} / P_{N A S}$ is 1.10 with the corresponding COV of 0.176 and the value of $\beta_{1}=2.37$ and $\beta_{2}=3.20$ for IOF loading condition, as shown in Table 6. It should be noted that the comparison of web crippling strengths predicted from FEA with the nominal web crippling strengths show negative values for ITF loading condition for some specimens, as shown in Table 8. This is because the cross-section geometries in the parametric study beyond the limitation of the inside corner radius-to-thickness ratio of $5\left(r_{i} / t \leq 5\right)$ as specified in the NAS 
Specification. Therefore, the mean value of the load ratio and the reliability index are not reported for ITF loading condition.

\section{Proposed design equation}

Cold-formed stainless steel square and rectangular hollow sections subjected to web crippling have two different types of failure. They are web buckling, where the web crippling capacity mainly depends on the stiffness of the material, and yielding in the web, where the web crippling capacity mainly depends on the yield strength of the material. The yield strength and stiffness of stainless steel reduces as the temperature increases. In this study, the proposed design web crippling equation takes into consideration of the reduced yield strength as well as stiffness at elevated temperatures for cold-formed high strength stainless steel square and rectangular hollow sections. Equation (1) is the proposed unified equation with coefficients $C, C_{R}, C_{N}$ and $C_{h}$.

$$
P_{P}=C t^{2} f_{y, T} \sin \theta\left(1-C_{R} \sqrt{\frac{r_{i}}{t}}\right)\left(1+C_{N} \sqrt{\frac{N}{t}}\right)\left(1-C_{h}\left(\frac{f_{y, T}}{E_{T}}\right) \sqrt{\frac{h}{t}}\right)
$$

where $C$ is the coefficient, $C_{R}$ is the inside corner radius coefficient, $C_{N}$ is the bearing length coefficient, $C_{h}$ is the web slenderness coefficient, $t$ is the thickness of the web, $f_{y, T}$ is the yield stress ( $\sigma_{0.2}$ proof stress) at a given temperature $\mathrm{T}$ in degree Celsius $\left({ }^{\circ} \mathrm{C}\right), \theta$ is the angle between the plane of the web and the plane of the bearing surface, $r_{i}$ is the inside corner radius, $N$ is the length of the bearing, $E_{T}$ is the elastic modulus at a given temperature $\mathrm{T}$ in degree Celsius $\left({ }^{\circ} \mathrm{C}\right)$, and $h$ is the depth of the flat portion of the web measured along the plane of the web. The coefficients are determined based on the numerical results obtained in this study as well as the experimental results, and the values of the coefficients are shown in Table 9. The limits of the proposed unified web crippling equation (Eq. (1)) at elevated temperatures are $h / t \leq 87, N / t \leq 100$, $N / h \leq 1.6, r_{i} / t \leq 5.5$ and $\theta=90^{\circ}$. 


\section{Comparison of numerical results with proposed design strengths at elevated temperatures}

The unfactored design strengths calculated using the proposed unified equation (1) were compared with the web crippling strengths $\left(P_{F E A}\right)$ predicted from the FEA. The proposed design strengths were calculated using the cross-section dimensions and material properties as those used in the parametric study. The resistance factor $\phi_{w 1}=0.70$ was obtained from reliability analysis. The load combination of $1.2 \mathrm{DL}+1.6 \mathrm{LL}$ was used to determine the reliability indices ( $\beta_{1}$ and $\left.\beta_{2}\right)$, as shown in Tables 5-8.

The proposed design strengths are generally conservative and reliable for EOF, IOF, ETF, and ITF loading conditions. The maximum mean value of the load ratio $P_{F E A} / P_{p}$ is 1.26 with the corresponding $\mathrm{COV}$ of 0.087 and the value of $\beta=4.32$ for ETF loading condition at elevated temperatures, as shown in Table 7 . The minimum mean value of the load ratio is 0.98 with the corresponding $\mathrm{COV}$ of 0.084 and the value of $\beta=3.37$ for ITF loading condition at elevated temperatures, as shown in Table 8 . The reliability indices $(\beta)$ are greater than the target value for all four loading conditions. The design strengths obtained from the proposed unified equation are more accurate than those predicted from the current design specifications.

\section{Comparison of experimental results with proposed design strengths at room temperature}

The web crippling test strengths of cold-formed high strength stainless steel square and rectangular hollow sections at room temperature conducted by Zhou and Young [13] were also compared with the design strengths obtained using the proposed unified equation, as shown in Tables $10-13$. The same values of the coefficients $C, C_{R}, C_{N}$ and $C_{h}$ for cold-formed high strength stainless steel tubular sections at elevated temperatures, as shown in Table 9, were used to calculate the proposed design strengths at room temperature. The load combination of $1.2 \mathrm{DL}+$ 1.6LL was used to compute the reliability index $(\beta)$. The design strengths are generally conservative and reliable for the four loading conditions. The maximum mean value of the load 
ratio $P_{E x p} / P_{p}$ is 1.12 with the corresponding COV of 0.081 and the value of $\beta=3.88$ for the ITF loading condition at room temperature, as shown in Table 13. The minimum mean value of the load ratio is 0.94 with the corresponding $\mathrm{COV}$ of 0.106 and the value of $\beta=3.06$ for the ETF loading condition at room temperature, as shown in Table 12. The reliability indices $(\beta)$ are greater than the target value for all loading conditions.

\section{Conclusions}

Numerical investigation of cold-formed high strength stainless steel square and rectangular hollow sections subjected to web crippling at elevated temperatures has been presented in this paper. A finite element model including geometric and material non-linearities has been developed and verified against experimental results. The finite element model closely predicted the behaviour of cold-formed high strength stainless steel square and rectangular hollow sections subjected to web crippling at room temperature. Hence, parametric study was carried out to study the structural performance of cold-formed stainless steel square and rectangular hollow sections subjected to web crippling at elevated temperatures. The web slenderness $(h / t)$ values of the hollow sections ranged from 13.7 to 87.0 , and the temperature ranged from 22 to $960^{\circ} \mathrm{C}$. The appropriateness of the web crippling design rules in the current specifications for cold-formed stainless steel at elevated temperatures has been examined. The web crippling strengths predicted from the finite element analysis were compared with the design strengths calculated from the current ASCE Specification, AS/NZS Standard and EC3 Code Part 1.4 for stainless steel structures by using the reduced material properties due to elevated temperatures. The NAS Specification for cold-formed carbon steel structural members was also used to predict the design strengths.

Finally, a unified web crippling equation for cold-formed high strength stainless steel tubular sections subjected to web crippling at elevated temperatures has been proposed. It is 
shown that the design strengths calculated using the proposed unified equation are generally conservative and reliable for the end-one-flange (EOF), interior-one-flange (IOF), end-two-flange (ETF) and interior-two-flange (ITF) loading conditions at elevated temperatures. It is also shown that the proposed design strengths are more accurate than the current design strengths predicted by the aforementioned specifications. In addition, the test results obtained by Zhou and Young [13] at room temperature for cold-formed high strength stainless steel square and rectangular hollow sections were also compared with the design strengths obtained using the proposed unified web crippling equation. It is shown that the design strengths obtained from the proposed unified web crippling equation are also generally conservative and reliable for the web crippling tests.

\section{Acknowledgements}

The research work described in this paper was supported by the Chinese National Natural Science Foundation (Project No. 51108337) and the Fundamental Research Funds for the Central Universities in China.

\section{References}

[1] Chen J. and Young B. Stress-strain curves for stainless steel at elevated temperatures. Engineering Structures 2006, 28, 229-239.

[2] Ng K.T. and Gardner L. Buckling of stainless steel columns and beams in fire. Engineering Structures 2007, 29, 717-730.

[3] Feng R. and Young B. Design of cold-formed stainless steel tubular joints at elevated temperatures. Engineering Structures 2012, 35, 188-202.

[4] Han L.H., Chen F., Liao F.Y., Tao Z., and Uy B. Fire performance of concrete filled stainless steel tubular columns. Engineering Structures 2013, 56, 165-181. 
[5] Zhao B. Material behaviour at elevated temperatures: Work package 5.1. ECSC project 'Development of the use of stainless steel in construction'. Contract No. 7210 SA/ 842. UK: The Steel Construction Institute, 2000.

[6] Zhao B. Évaluation de la résistance au feu des elements structuraux en acier inoxydable. Construction Métallique 2002, 4, 55-64.

[7] Ala-Outinen T. Fire resistance of austenitic stainless steels Polarit 725 (EN 1.4301) and Polarit 761 (EN 1.4571) VTT Research Notes 1760. Espoo, Finland, 1996.

[8] Hoke J.H. Handbook of stainless steels. McGraw-Hill, 1977.

[9] American Society of Civil Engineers. Specification for the design of cold-formed stainless steel structural members. SEI/ASCE-8-02, Reston, Virginia, 2002.

[10] Australian/New Zealand Standard. Cold-formed stainless steel structures. AS/NZS 4673:2001, Standards Australia, Sydney, Australia, 2001.

[11] EC3. Design of steel structures - Part 1.4: General rules - Supplementary rules for stainless steels. European Committee for Standardization, ENV 1993-1-4, Brussels; 2006.

[12] ABAQUS Standard User's Manual. Hibbitt, Karlsson and Sorensen, Inc. Vols. 1-3, Version 6.8, USA, 2008.

[13] Zhou F. and Young B. Cold-formed high strength stainless steel tubular sections subjected to web crippling. Journal of Structural Engineering, ASCE 2007, 133(3).

[14] AISI S100. North American Specification for the design of cold-formed steel structural members. North American Cold-formed Steel Specification, American Iron and Steel Institute, AISI S100-2007, Washington, D.C.; 2007.

[15] ASTM E8/E8M-11. Standard Test Methods for Tension Testing for Metallic Materials. E8/E8M-11. West Conshohocken, USA: American Society for Testing and Materials; 2011. 
[16] AS. Metallic materials - Tensile testing at ambient temperature. Australian Standard, AS 1391-2007. Sydney (Australia): Standards Association of Australia; 2007.

[17] Young B. and Lui W.M. Behavior of cold-formed high strength stainless steel sections. Journal of Structural Engineering, ASCE 2005, 131(11), 1738-1745.

[18] Gardner L. and Nethercot D.A. Experiments on stainless steel hollow sections - Part1: Material and cross section behaviour. Journal of Constructional Steel Research 2004, 60(9), 1291-1318.

[19] American Society of Civil Engineers Standard. Minimum design loads for buildings and other structures. ASCE Standard 7-05, New York, 2005.

[20] American Society of Civil Engineers. Commentary on Specification for the design of coldformed stainless steel structural members. SEI/ASCE-8-02, Reston, Virginia, 2002.

[21] Commentary on North American Specification for the design of cold-formed steel structural members. American Iron and Steel Institute, Washington, D.C, 2001.

[22] EC3. Design of steel structures - Part 1.1: General rules and rules for buildings. European Committee for Standardization, ENV 1993-1-1, Brussels; 2005.

[23] EC3. Design of steel structures - Part 1.3: General rules - Supplementary rules for coldformed members and sheeting. European Committee for Standardization, ENV 1993-1-3, Brussels; 2006.

\section{NOTATION}

The following symbols are used in this paper:

$b_{f} \quad=$ overall width of flange;

$b_{f c} \quad=$ flange width between the midlines of the webs;

C = web crippling coefficient;

$C_{h} \quad=$ web slenderness coefficient; 
$C_{N} \quad$ = bearing length coefficient;

$C_{R} \quad=$ inside corner radius coefficient;

$\mathrm{COV}=$ coefficient of variation;

$d \quad=$ overall depth of web;

$d_{c} \quad=$ web depth between the midlines of the flanges;

$E \quad=$ Young's modulus of elasticity;

$E_{T} \quad=$ elastic modulus at temperature $T^{\circ} \mathrm{C}$;

$F_{m} \quad=$ mean value of fabrication factor;

$f_{y} \quad=$ yield stress $(0.2 \%$ proof stress $) ;$

$f_{y, T} \quad=$ yield stress $(0.2 \%$ proof stress $)$ at temperature $T^{\circ} \mathrm{C}$;

$h \quad=$ depth of flat portion of web measured along the plane of web;

$L \quad=$ actual length of test specimen;

$M_{m} \quad=$ mean value of material factor;

$N \quad=$ length of bearing;

$P \quad=$ nominal web crippling strength;

$P_{A S C E}=$ nominal web crippling strength obtained from ASCE Specification and AS/NAS Standard;

$P_{E C 3}=$ nominal web crippling strength obtained from European code;

$P_{\text {Exp }} \quad=$ experimental ultimate web crippling load per web;

$P_{F E A}=$ web crippling strength predicted from finite element analysis;

$P_{F E A, T}=$ web crippling strength predicted from finite element analysis at temperature $T^{\circ} \mathrm{C}$;

$P_{m} \quad=$ mean value of load ratio;

$P_{\text {NAS }}=$ nominal web crippling strength obtained from NAS Specification;

$P_{p} \quad=$ proposed web crippling strength calculated;

$r_{i} \quad=$ inside corner radius; 


$$
\begin{array}{ll}
r_{c} & =\text { midline corner radius; } \\
t & =\text { web thickness; } \\
V_{F} & =\text { coefficient of variation of fabrication factor; } \\
V_{M} & =\text { coefficient of variation of material factor; } \\
V_{p} & =\text { coefficient of variation of load ratio; } \\
\beta & =\text { reliability index; } \\
\beta_{1} & =\text { reliability index determined using } \phi_{w 1} ; \\
\beta_{2} & =\text { reliability index determined using } \phi_{w 2} ; \\
\theta & =\text { angle between the plane of web and the plane of bearing surface; } \\
\varepsilon & =\text { strain; } \\
\varepsilon_{f} & =\text { elongation (longitudinal tensile strain) after fracture based on gauge length of } 50 \text { mm; } \\
\phi_{w} & =\text { resistance (capacity) factor; } \\
\phi_{w 2} & =\text { resistance } \\
\sigma_{u} & =\text { tensile strength; } \\
\sigma_{0.2} & =0.2 \% \text { tensile proof stress; } \\
& =\text { capacity) factor specified in the current specifications; and }
\end{array}
$$




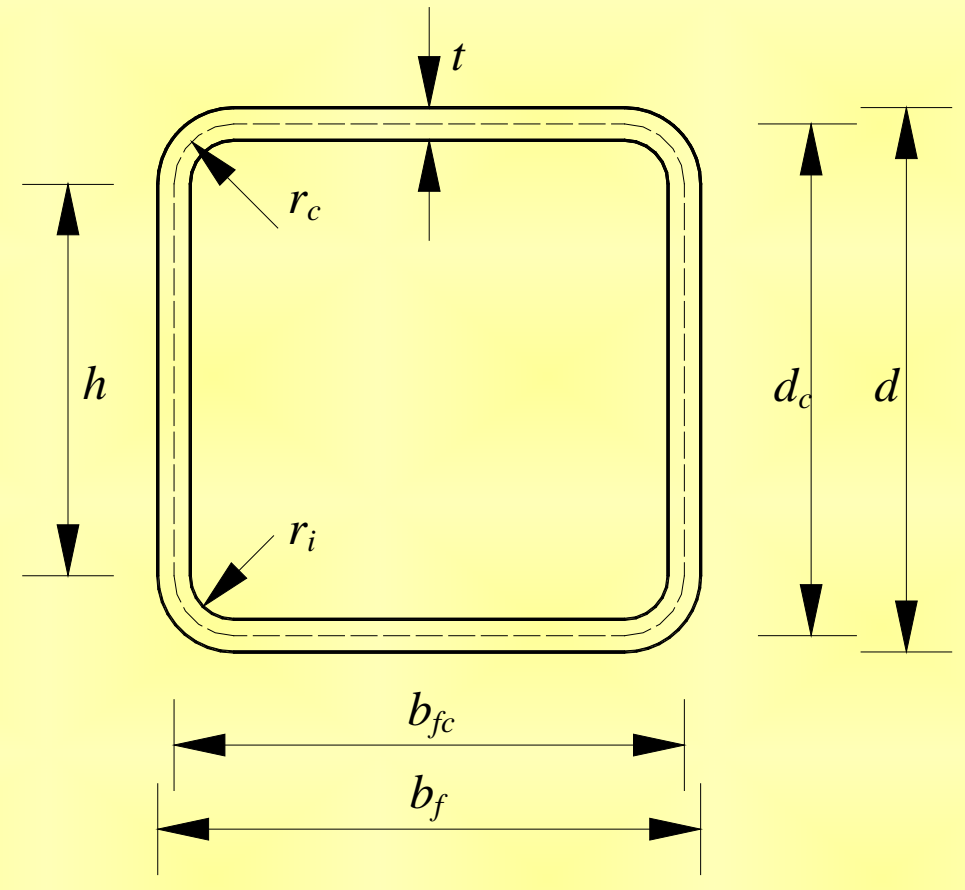

(a) Definition of symbols

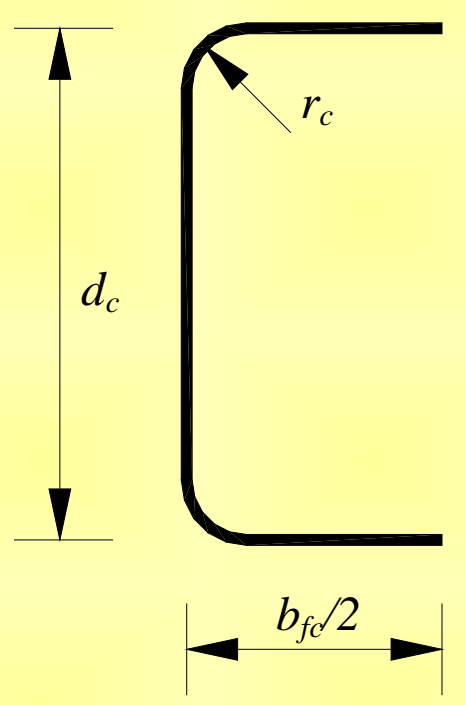

(b) Half section due to symmetry

Figure 1. Stainless steel cross-section 


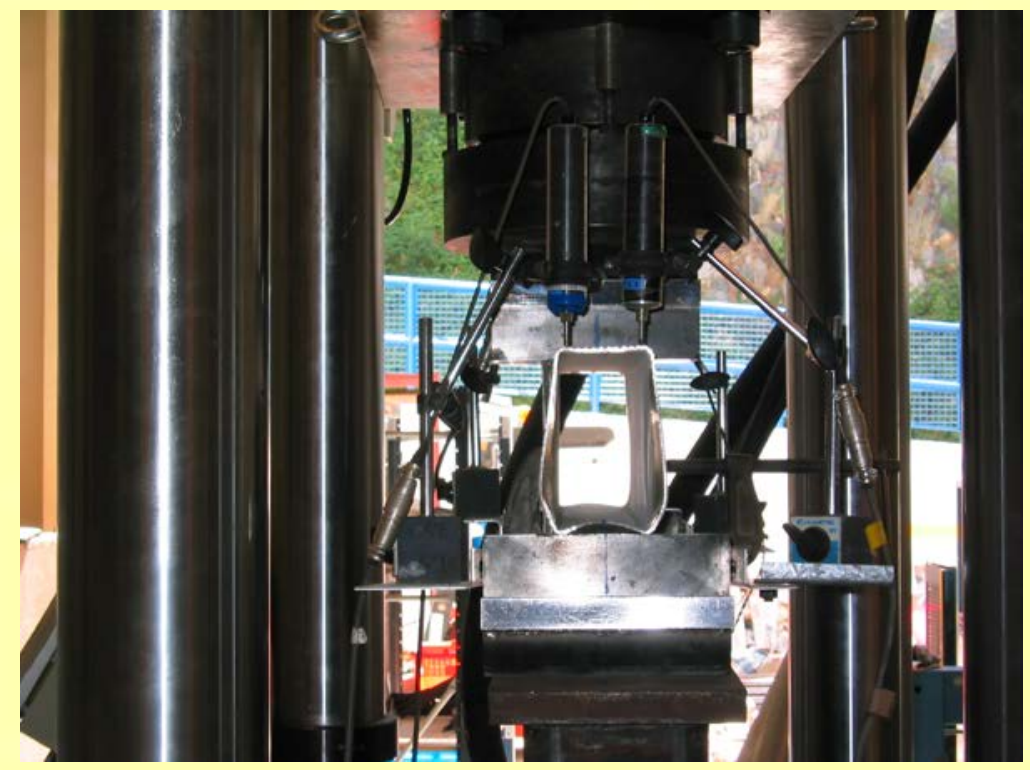

(a) Experimental

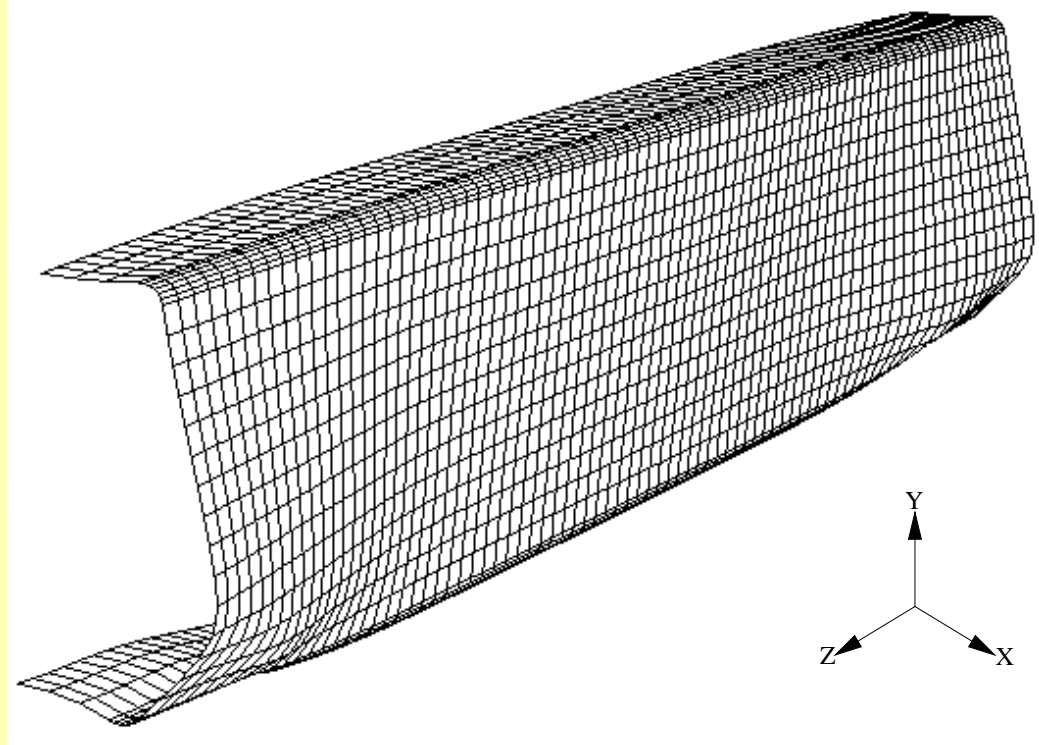

(b) FEA

Figure 2. Comparison of experimental and finite element analysis failure mode for End-One-Flange (EOF) loading condition 


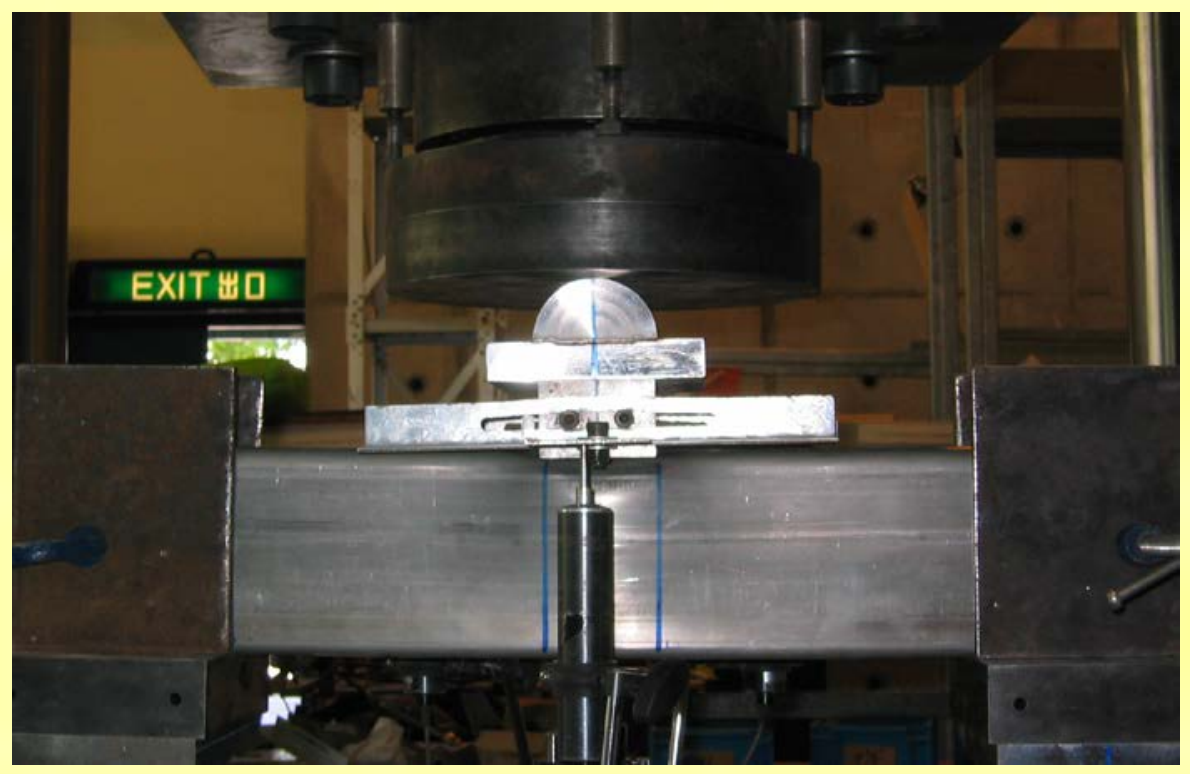

(a) Experimental

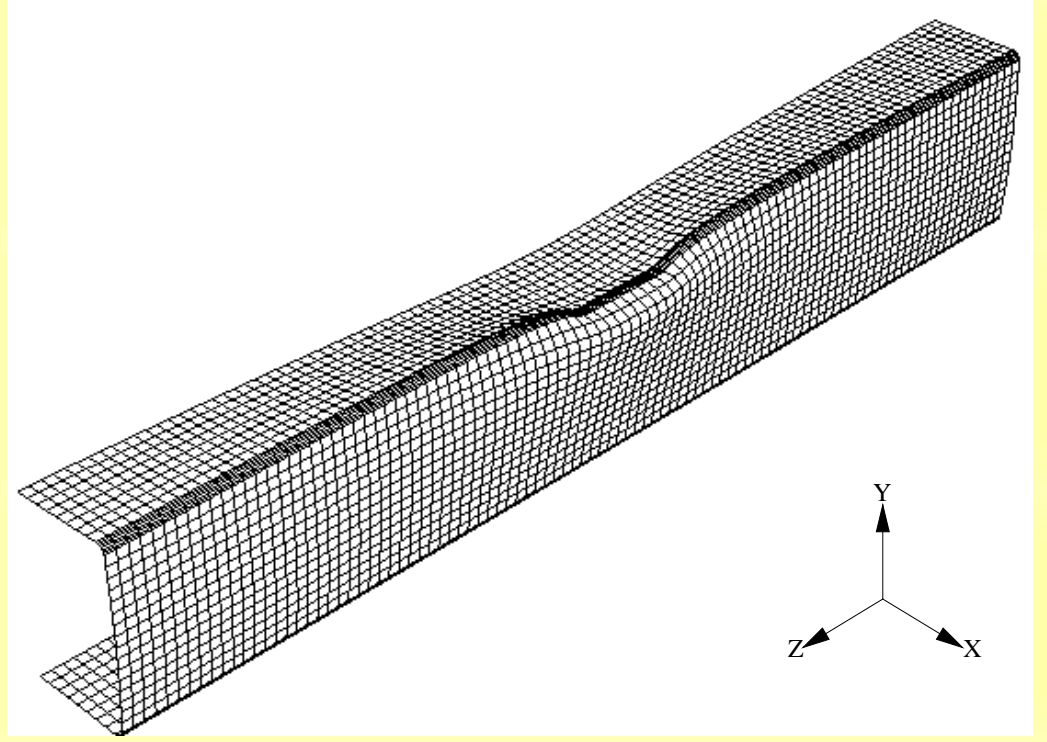

(b) FEA

Figure 3. Comparison of experimental and finite element analysis failure mode for Interior-One-Flange (IOF) loading condition 


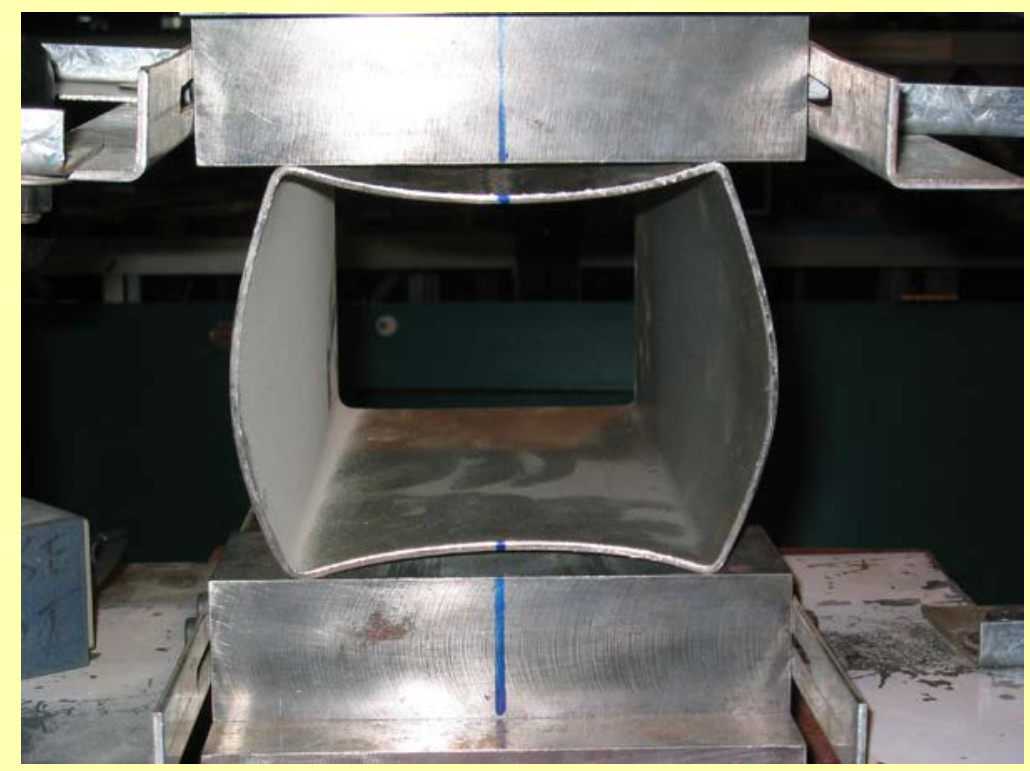

(a) Experimental

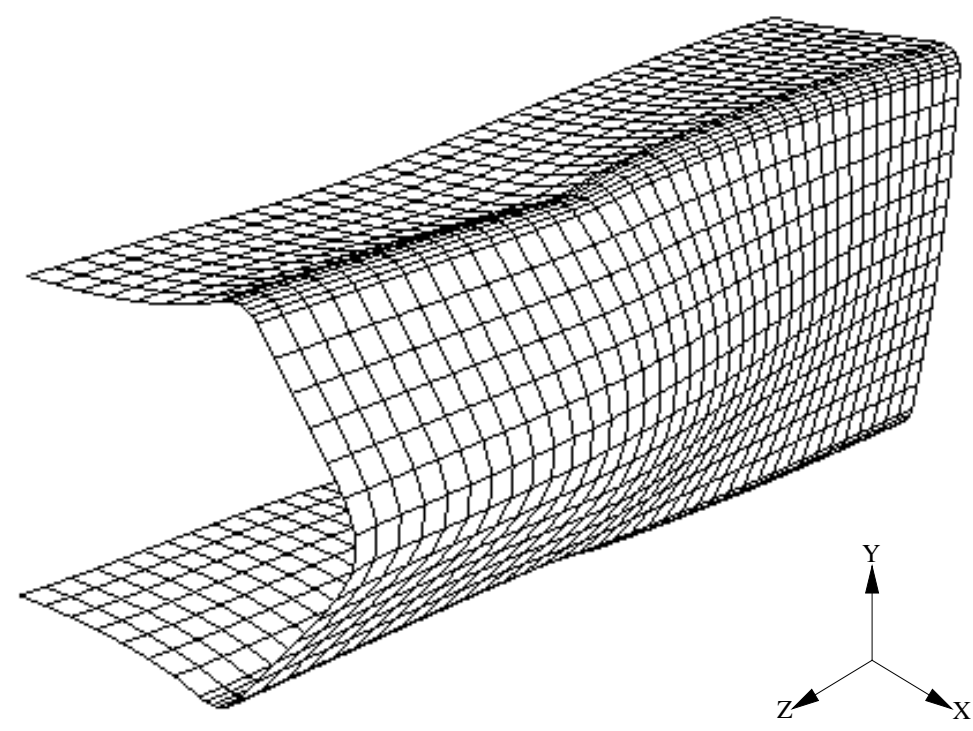

(b) FEA

Figure 4. Comparison of experimental and finite element analysis failure mode for End-Two-Flange (ETF) loading condition 


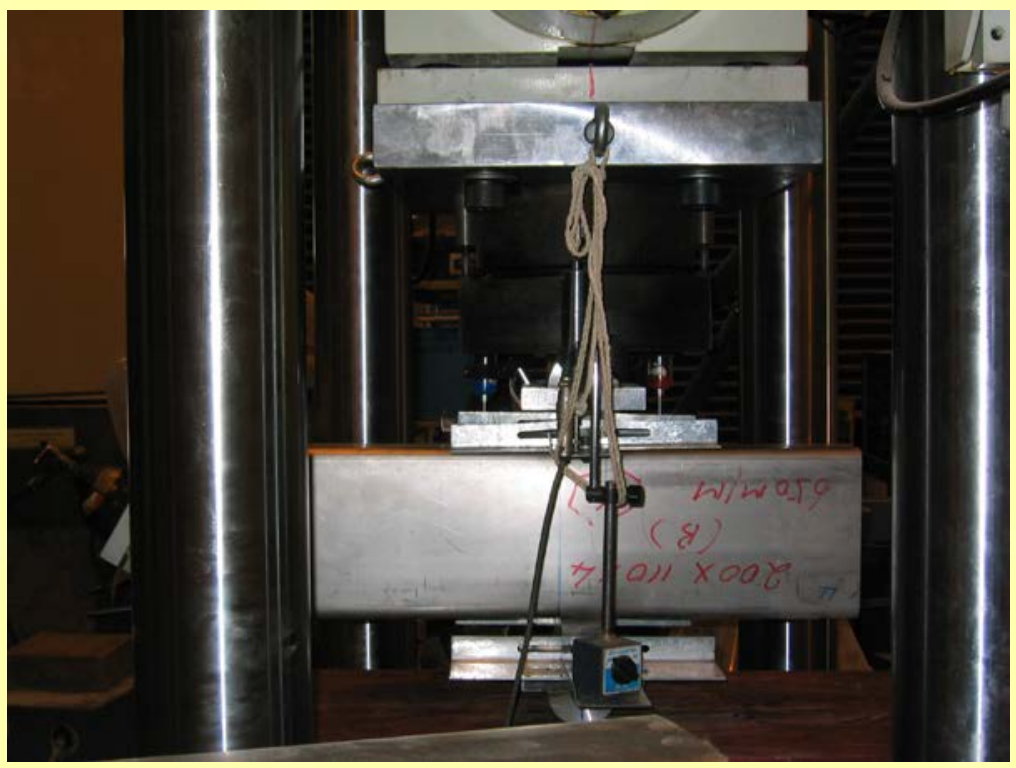

(a) Experimental

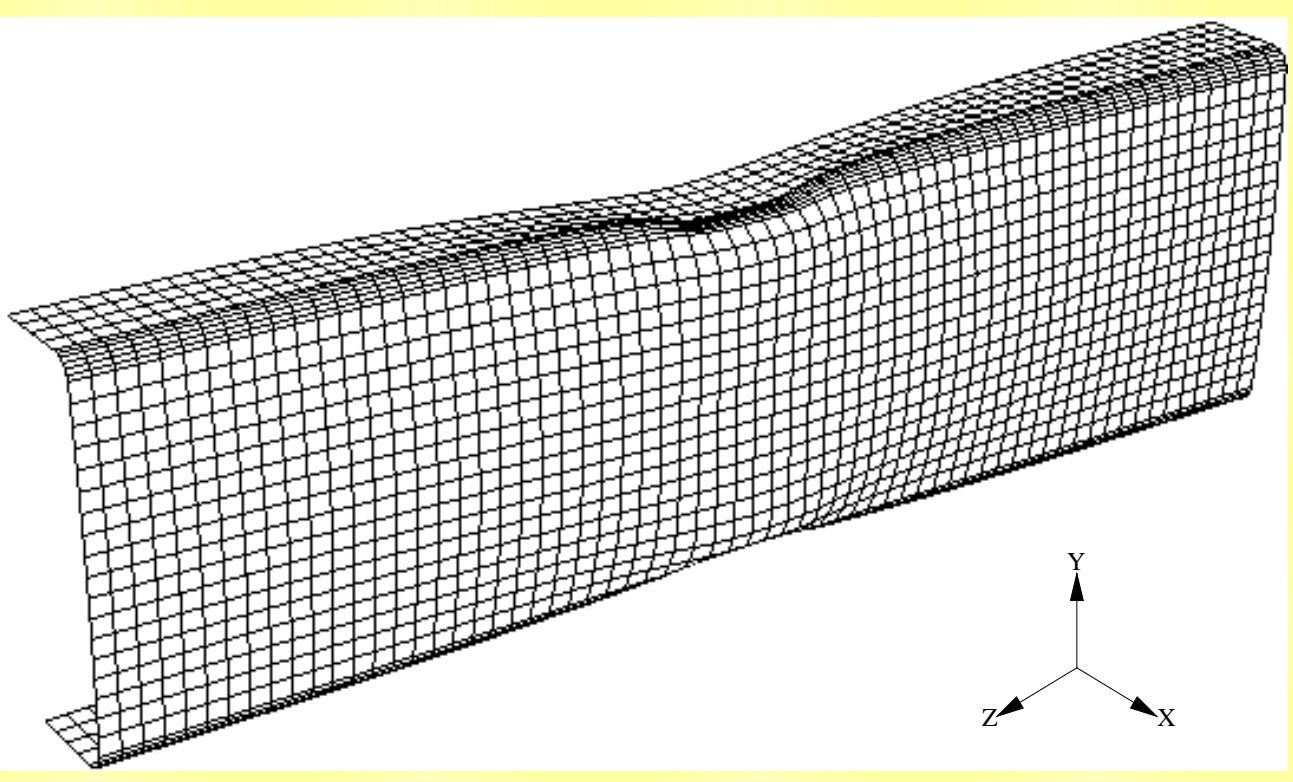

(b) FEA

Figure 5. Comparison of experimental and finite element analysis failure mode for Interior-Two-Flange (ITF) loading condition 


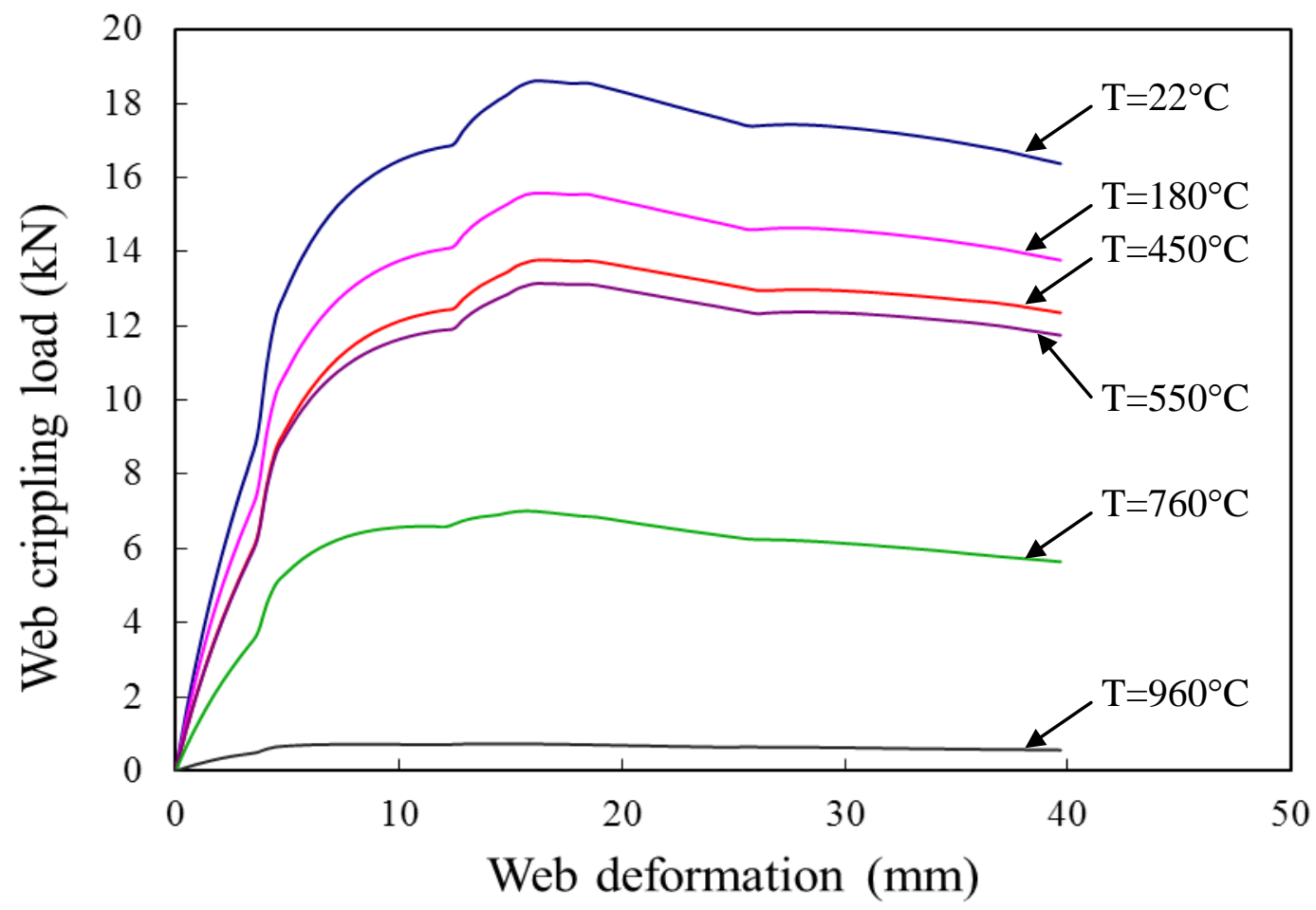

Figure 6. Load-web deformation curves for Section $200 \times 200 \times 2$ under ETF loading condition

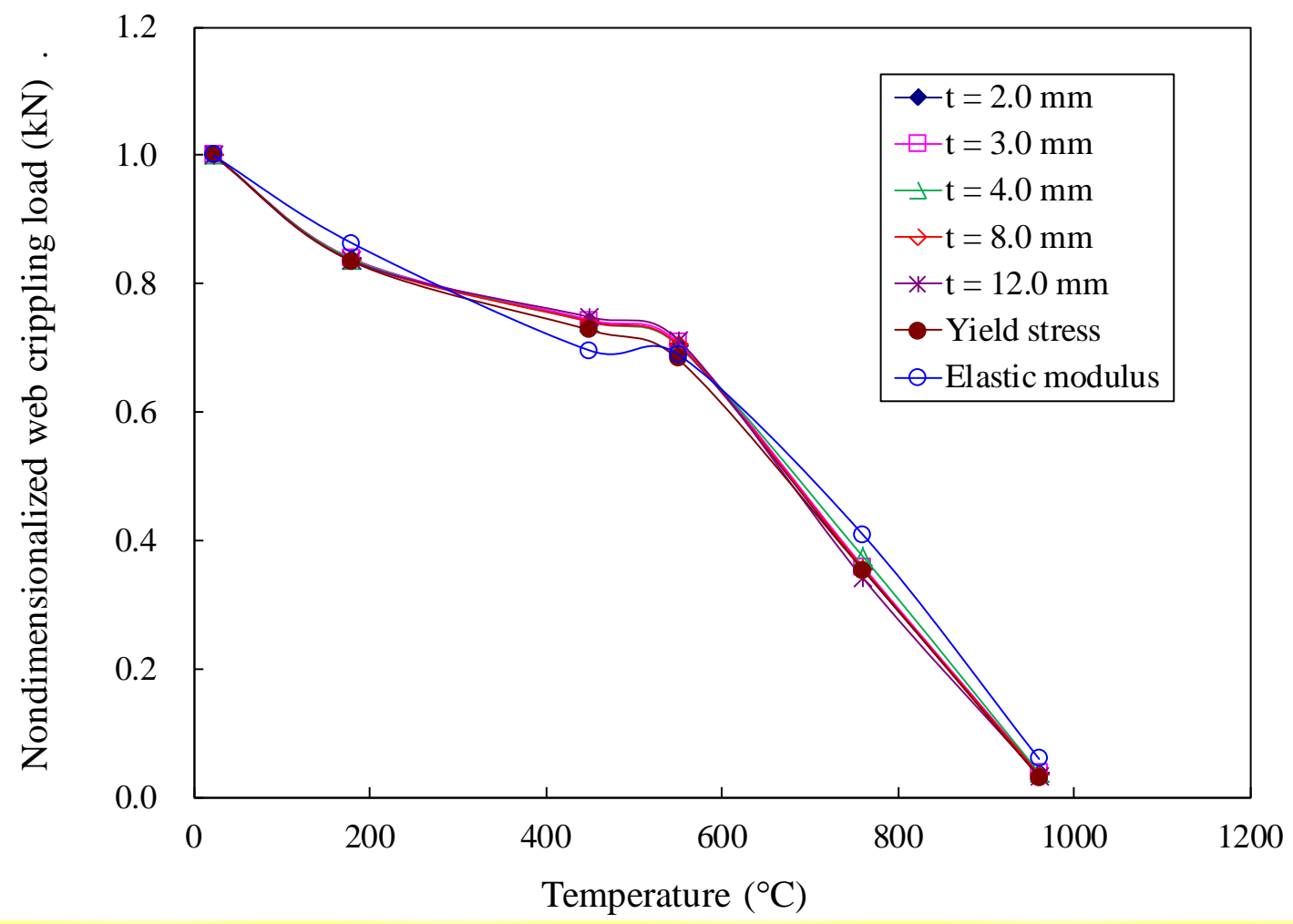

Figure 7. Comparison of reduction factor for ETF loading condition 


\begin{tabular}{|c|c|c|c|c|c|c|}
\hline \multirow{2}{*}{ Test Series } & \multirow{2}{*}{$\begin{array}{l}\text { Section } \\
d \times b_{f} \times t\end{array}$} & \multirow{2}{*}{ Туре } & $E$ & $\sigma_{0.2}$ & $\sigma_{u}$ & $\varepsilon_{f}$ \\
\hline & & & GPa & $\mathrm{MPa}$ & $\mathrm{MPa}$ & $\%$ \\
\hline SHS1 & $40 \times 40 \times 2$ & Duplex & 216 & 707 & 827 & 29 \\
\hline SHS2 & $50 \times 50 \times 1.5$ & Duplex & 200 & 622 & 770 & 37 \\
\hline SHS3 & $150 \times 150 \times 3$ & $\mathrm{HSA}^{\mathrm{a}}$ & 189 & 448 & 699 & 52 \\
\hline SHS4 & $150 \times 150 \times 6$ & $\mathrm{HSA}^{\mathrm{a}}$ & 194 & 497 & 761 & 52 \\
\hline RHS1 & $140 \times 80 \times 3$ & Duplex & 212 & 486 & 736 & 47 \\
\hline RHS2 & $160 \times 80 \times 3$ & Duplex & 208 & 536 & 766 & 40 \\
\hline RHS3 & $200 \times 110 \times 4$ & $\mathrm{HSA}^{\mathrm{a}}$ & 200 & 503 & 961 & 36 \\
\hline
\end{tabular}

Note: ${ }^{\text {a }}$ HSA $=$ High Strength Austenitic

Table 1. Material Properties obtained from Tensile Coupon Tests [17] 


\begin{tabular}{|c|c|c|c|c|}
\hline \multirow{3}{*}{ Specimen } & Web slenderness & $\begin{array}{l}\text { Exp. load per web } \\
\text { (From Ref. [13]) }\end{array}$ & FEA load per web & Comparison \\
\hline & \multirow{2}{*}{$h / t$} & $P_{E x p}$ & $P_{F E A}$ & \multirow{2}{*}{$P_{E x p} / P_{F E A}$} \\
\hline & & $(\mathrm{kN})$ & $(\mathrm{kN})$ & \\
\hline EOF140×80×3N75 & 39.4 & 37.6 & 38.1 & 0.99 \\
\hline EOF140×80×3N50 & 39.3 & 33.6 & 32.2 & 1.04 \\
\hline EOF150×150×6N75 & 22.2 & 124.3 & 126.2 & 0.98 \\
\hline EOF160×80×3N75 & 49.6 & 32.4 & 35.5 & 0.91 \\
\hline EOF160×80×3N50 & 49.6 & 29.6 & 31.6 & 0.94 \\
\hline EOF200×110×4N100 & 45.1 & 60.2 & 63.3 & 0.95 \\
\hline IOF50×50×1.5N50 & 28.8 & 21.7 & 23.9 & 0.91 \\
\hline IOF50×50×1.5N25 & 28.7 & 19.2 & 18.5 & 1.04 \\
\hline IOF150×150×3N150 & 48.4 & 59.3 & 62.9 & 0.94 \\
\hline IOF150×150×3N75 & 48.6 & 51.4 & 47.2 & 1.09 \\
\hline IOF150×150×6N150 & 22.7 & 228.9 & 247.2 & 0.93 \\
\hline IOF150×150×6N75 & 22.1 & 207.0 & 191.6 & 1.08 \\
\hline IOF200×110×4N100 & 43.2 & 98.6 & 105.7 & 0.93 \\
\hline IOF $200 \times 110 \times 4 N 50$ & 44.6 & 82.3 & 79.1 & 1.04 \\
\hline ETF150×150×3N150 & 48.7 & 28.2 & 30.1 & 0.94 \\
\hline ETF150×150×3N75 & 48.5 & 20.0 & 20.8 & 0.96 \\
\hline ETF150×150×6N150 & 21.6 & 148.3 & 161.2 & 0.92 \\
\hline ETF150×150×6N75 & 22.3 & 95.8 & 102.3 & 0.94 \\
\hline ETF160×80×3N75 & 49.7 & 23.1 & 25.4 & 0.91 \\
\hline ETF160×80×3N50 & 49.6 & 20.7 & 21.5 & 0.96 \\
\hline ITF40×40×2N50 & 16.9 & 35.3 & 34.0 & 1.04 \\
\hline ITF40×40×2N25 & 16.8 & 29.0 & 27.2 & 1.07 \\
\hline ITF140×80×3N75 & 39.3 & 61.1 & 57.3 & 1.07 \\
\hline ITF $140 \times 80 \times 3 N 50$ & 39.2 & 56.1 & 58.9 & 0.95 \\
\hline ITF160×80×3N75 & 49.4 & 63.1 & 64.9 & 0.97 \\
\hline ITF160×80×3N50 & 49.5 & 56.6 & 58.3 & 0.97 \\
\hline ITF200×110×4N100 & 43.0 & 115.3 & 107.4 & 1.07 \\
\hline ITF200×110×4N50 & 45.1 & 90.6 & 86.8 & 1.04 \\
\hline & & & Mean & 0.99 \\
\hline & & & $\mathrm{COV}$ & 0.061 \\
\hline
\end{tabular}

Table 2. Comparison of Experimental Results [13] with Web Crippling Strengths Predicted from Finite Element Analysis 


\begin{tabular}{|c|c|c|c|c|c|c|c|c|c|c|c|c|}
\hline \multirow{4}{*}{$\begin{array}{c}\mathrm{T} \\
\left({ }^{\circ} \mathrm{C}\right)\end{array}$} & \multirow{4}{*}{$\begin{array}{l}\text { Section } \\
d \times b_{f} \times t\end{array}$} & \multirow{4}{*}{$\begin{array}{c}\text { Radius } \\
r_{i} \\
(\mathrm{~mm})\end{array}$} & \multicolumn{4}{|c|}{ Ratio } & \multirow{4}{*}{$\begin{array}{c}\begin{array}{c}\text { Yield } \\
\text { stress }\end{array} \\
f_{y, T} \\
(\mathrm{MPa})\end{array}$} & \multirow{4}{*}{$\begin{array}{c}\begin{array}{c}\text { Elastic } \\
\text { Modulus }\end{array} \\
E_{T} \\
(\mathrm{MPa})\end{array}$} & \multirow{2}{*}{\multicolumn{4}{|c|}{$\begin{array}{c}\text { FEA load per web } \\
\qquad P_{\text {FEA }}\end{array}$}} \\
\hline & & & \multirow[t]{3}{*}{$h / t$} & \multirow[t]{3}{*}{$r_{i} / t$} & \multirow[t]{3}{*}{$N / t$} & \multirow[t]{3}{*}{$N / h$} & & & & & & \\
\hline & & & & & & & & & EOF & IOF & ETF & ITF \\
\hline & & & & & & & & & $(\mathrm{kN})$ & $(\mathrm{kN})$ & $(\mathrm{kN})$ & $(\mathrm{kN})$ \\
\hline 22 & & 11.0 & 87.0 & 5.5 & 100.0 & 1.1 & 731 & 227000 & 26.4 & 50.4 & 18.6 & 33.0 \\
\hline 180 & & 11.0 & 87.0 & 5.5 & 100.0 & 1.1 & 610 & 195901 & 22.2 & 42.8 & 15.6 & 27.7 \\
\hline 450 & (200 & 11.0 & 87.0 & 5.5 & 100.0 & 1.1 & 532 & 157992 & 19.6 & 38.1 & 13.8 & 24.4 \\
\hline 550 & $200 \times 200 \times 2$ & 11.0 & 87.0 & 5.5 & 100.0 & 1.1 & 499 & 156630 & 18.6 & 36.4 & 13.1 & 23.2 \\
\hline 760 & & 11.0 & 87.0 & 5.5 & 100.0 & 1.1 & 259 & 92843 & 10.2 & 18.0 & 6.6 & 12.7 \\
\hline 960 & & 11.0 & 87.0 & 5.5 & 100.0 & 1.1 & 23 & 13620 & 1.1 & 2.0 & 0.7 & 1.3 \\
\hline 22 & & 10.5 & 57.7 & 3.5 & 66.7 & 1.2 & 731 & 227000 & 68.4 & 108.3 & 48.4 & 81.7 \\
\hline 180 & & 10.5 & 57.7 & 3.5 & 66.7 & 1.2 & 610 & 195901 & 57.4 & 90.5 & 40.6 & 68.5 \\
\hline 450 & $200 \times 000 \times$ & 10.5 & 57.7 & 3.5 & 66.7 & 1.2 & 532 & 157992 & 50.8 & 80.6 & 36.0 & 60.5 \\
\hline 550 & $200 \times 200 \times 0$ & 10.5 & 57.7 & 3.5 & 66.7 & 1.2 & 499 & 156630 & 48.4 & 77.1 & 34.3 & 57.5 \\
\hline 760 & & 10.5 & 57.7 & 3.5 & 66.7 & 1.2 & 259 & 92843 & 24.3 & 37.6 & 17.4 & 30.4 \\
\hline 960 & & 10.5 & 57.7 & 3.5 & 66.7 & 1.2 & 23 & 13620 & 2.5 & 3.9 & 1.8 & 3.1 \\
\hline 22 & & 10.0 & 43.0 & 2.5 & 50.0 & 1.2 & 731 & 227000 & 120.7 & 186.9 & 88.3 & 150.2 \\
\hline 180 & & 10.0 & 43.0 & 2.5 & 50.0 & 1.2 & 610 & 195901 & 101.2 & 156.5 & 74.0 & 126.0 \\
\hline 450 & גבת & 10.0 & 43.0 & 2.5 & 50.0 & 1.2 & 532 & 157992 & 90.5 & 141.2 & 65.4 & 111.5 \\
\hline 550 & $200 \times \angle 00 \times 4$ & 10.0 & 43.0 & 2.5 & 50.0 & 1.2 & 499 & 156630 & 86.3 & 134.8 & 62.2 & 106.1 \\
\hline 760 & & 10.0 & 43.0 & 2.5 & 50.0 & 1.2 & 259 & 92843 & 41.7 & 58.4 & 33.1 & 52.6 \\
\hline 960 & & 8.0 & 43.0 & 2.5 & 50.0 & 1.2 & 23 & 13620 & 4.3 & 6.5 & 3.4 & 5.4 \\
\hline 22 & & 8.0 & 21.0 & 1.0 & 25.0 & 1.2 & 731 & 227000 & 501.7 & 698.0 & 420.8 & 590.9 \\
\hline 180 & & 8.0 & 21.0 & 1.0 & 25.0 & 1.2 & 610 & 195901 & 421.2 & 584.9 & 351.8 & 494.2 \\
\hline 450 & & 8.0 & 21.0 & 1.0 & 25.0 & 1.2 & 532 & 157992 & 375.0 & 526.2 & 311.7 & 439.5 \\
\hline 550 & $200 \times 200 \times 0$ & 8.0 & 21.0 & 1.0 & 25.0 & 1.2 & 499 & 156630 & 356.0 & 501.0 & 296.7 & 418.3 \\
\hline 760 & & 8.0 & 21.0 & 1.0 & 25.0 & 1.2 & 259 & 92843 & 178.9 & 241.4 & 150.2 & 210.3 \\
\hline 960 & & 6.0 & 21.0 & 1.0 & 25.0 & 1.2 & 23 & 13620 & 17.8 & 24.4 & 15.1 & 21.2 \\
\hline 22 & & 6.0 & 13.7 & 0.5 & 16.7 & 1.2 & 731 & 227000 & 1056.6 & 1563.4 & 993.0 & 1346.8 \\
\hline 180 & & 6.0 & 13.7 & 0.5 & 16.7 & 1.2 & 610 & 195901 & 882.9 & 1318.9 & 829.8 & 1126.4 \\
\hline 450 & & 6.0 & 13.7 & 0.5 & 16.7 & 1.2 & 532 & 157992 & 795.7 & 1195.9 & 742.8 & 1010.7 \\
\hline 550 & $200 \times \angle 00 \wedge 12$ & 6.0 & 13.7 & 0.5 & 16.7 & 1.2 & 499 & 156630 & 758.6 & 1135.8 & 707.5 & 962.9 \\
\hline 760 & & 6.0 & 13.7 & 0.5 & 16.7 & 1.2 & 259 & 92843 & 353.5 & 527.9 & 339.0 & 464.3 \\
\hline 960 & & 6.0 & 13.7 & 0.5 & 16.7 & 1.2 & 23 & 13620 & 34.9 & 52.3 & 33.7 & 46.3 \\
\hline
\end{tabular}

Table 3. Cross-section Dimensions and Web Crippling Strengths Predicted from Finite Element

Analysis of Parametric Study 


\begin{tabular}{|c|c|c|c|c|c|c|c|}
\hline \multirow{3}{*}{$\mathrm{T}$} & \multirow{3}{*}{ Section } & \multicolumn{6}{|c|}{ Reduction factor } \\
\hline & & \multicolumn{4}{|c|}{$\begin{array}{l}\text { Ultimate load } \\
\frac{P_{F E A, T}}{P_{F E A, T=22^{\circ}}}\end{array}$} & \multirow[t]{2}{*}{$\begin{array}{c}\text { Yield stress } \\
\text { (From Ref. [1]) } \\
\frac{f_{y, T}}{f_{y, T=22^{\circ}}}\end{array}$} & \multirow[t]{2}{*}{$\begin{array}{l}\text { Elastic Modulus } \\
\text { (From Ref. [1]) } \\
\frac{E_{T}}{E_{T=22^{\circ}}}\end{array}$} \\
\hline & & EOF & IOF & ETF & ITF & & \\
\hline \multicolumn{8}{|l|}{$\left({ }^{\circ} \mathrm{C}\right)$} \\
\hline 22 & \multirow{6}{*}{$200 \times 200 \times 2$} & 1.00 & 1.00 & 1.00 & 1.00 & 1.00 & 1.00 \\
\hline 180 & & 0.84 & 0.85 & 0.84 & 0.84 & 0.83 & 0.86 \\
\hline 450 & & 0.74 & 0.76 & 0.74 & 0.74 & 0.73 & 0.70 \\
\hline 550 & & 0.70 & 0.72 & 0.70 & 0.70 & 0.68 & 0.69 \\
\hline 760 & & 0.39 & 0.36 & 0.35 & 0.38 & 0.35 & 0.41 \\
\hline 960 & & 0.04 & 0.04 & 0.04 & 0.04 & 0.03 & 0.06 \\
\hline 22 & \multirow{6}{*}{$200 \times 200 \times 3$} & 1.00 & 1.00 & 1.00 & 1.00 & 1.00 & 1.00 \\
\hline 180 & & 0.84 & 0.84 & 0.84 & 0.84 & 0.83 & 0.86 \\
\hline 450 & & 0.74 & 0.74 & 0.74 & 0.74 & 0.73 & 0.70 \\
\hline 550 & & 0.71 & 0.71 & 0.71 & 0.70 & 0.68 & 0.69 \\
\hline 760 & & 0.36 & 0.35 & 0.36 & 0.37 & 0.35 & 0.41 \\
\hline 960 & & 0.04 & 0.04 & 0.04 & 0.04 & 0.03 & 0.06 \\
\hline 22 & \multirow{6}{*}{$200 \times 200 \times 4$} & 1.00 & 1.00 & 1.00 & 1.00 & 1.00 & 1.00 \\
\hline 180 & & 0.84 & 0.84 & 0.84 & 0.84 & 0.83 & 0.86 \\
\hline 450 & & 0.75 & 0.76 & 0.74 & 0.74 & 0.73 & 0.70 \\
\hline 550 & & 0.71 & 0.72 & 0.70 & 0.71 & 0.68 & 0.69 \\
\hline 760 & & 0.35 & 0.31 & 0.37 & 0.35 & 0.35 & 0.41 \\
\hline 960 & & 0.04 & 0.03 & 0.04 & 0.04 & 0.03 & 0.06 \\
\hline 22 & \multirow{6}{*}{$200 \times 200 \times 8$} & 1.00 & 1.00 & 1.00 & 1.00 & 1.00 & 1.00 \\
\hline 180 & & 0.84 & 0.84 & 0.84 & 0.84 & 0.83 & 0.86 \\
\hline 450 & & 0.75 & 0.75 & 0.74 & 0.74 & 0.73 & 0.70 \\
\hline 550 & & 0.71 & 0.72 & 0.71 & 0.71 & 0.68 & 0.69 \\
\hline 760 & & 0.36 & 0.35 & 0.36 & 0.36 & 0.35 & 0.41 \\
\hline 960 & & 0.04 & 0.03 & 0.04 & 0.04 & 0.03 & 0.06 \\
\hline 22 & \multirow{6}{*}{$200 \times 200 \times 12$} & 1.00 & 1.00 & 1.00 & 1.00 & 1.00 & 1.00 \\
\hline 180 & & 0.84 & 0.84 & 0.84 & 0.84 & 0.83 & 0.86 \\
\hline 450 & & 0.75 & 0.76 & 0.75 & 0.75 & 0.73 & 0.70 \\
\hline 550 & & 0.72 & 0.73 & 0.71 & 0.71 & 0.68 & 0.69 \\
\hline 760 & & 0.33 & 0.34 & 0.34 & 0.34 & 0.35 & 0.41 \\
\hline 960 & & 0.03 & 0.03 & 0.03 & 0.03 & 0.03 & 0.06 \\
\hline
\end{tabular}

Table 4. Reduction Factors 


\begin{tabular}{|c|c|c|c|c|c|c|}
\hline \multirow{4}{*}{$\mathrm{T}$} & \multirow{5}{*}{ Section } & \multirow{2}{*}{$\begin{array}{c}\text { FEA } \\
\text { EOF }\end{array}$} & \multicolumn{4}{|c|}{ Comparison } \\
\hline & & & ASCE & EC3 & NAS & Proposed \\
\hline & & $P_{\text {- }}$ & $P_{F E A}$ & $P_{F E A}$ & $P_{F E A}$ & $P_{F E A}$ \\
\hline & & FEA & $\overline{P_{A S C E}}$ & $\overline{P_{E C 3}}$ & $\overline{P_{N A S}}$ & $\overline{P_{p}}$ \\
\hline$\left({ }^{\circ} \mathrm{C}\right)$ & & $(\mathrm{kN})$ & & & & \\
\hline 22 & \multirow{6}{*}{$200 \times 200 \times 2$} & 26.4 & 2.33 & 4.23 & 0.92 & 1.01 \\
\hline 180 & & 22.2 & 1.96 & 4.19 & 0.93 & 1.02 \\
\hline 450 & & 19.6 & 1.73 & 4.41 & 0.94 & 1.03 \\
\hline 550 & & 18.6 & 1.64 & 4.34 & 0.95 & 1.05 \\
\hline 760 & & 10.2 & 1.11 & 4.29 & 1.00 & 1.10 \\
\hline 960 & & 1.1 & 0.99 & 4.06 & 1.22 & 1.34 \\
\hline 22 & \multirow{6}{*}{$200 \times 200 \times 3$} & 68.4 & 2.60 & 4.94 & 1.08 & 1.09 \\
\hline 180 & & 57.4 & 2.19 & 4.88 & 1.08 & 1.09 \\
\hline 450 & & 50.8 & 1.93 & 5.15 & 1.10 & 1.11 \\
\hline 550 & & 48.4 & 1.84 & 5.09 & 1.12 & 1.13 \\
\hline 760 & & 24.3 & 1.14 & 4.61 & 1.08 & 1.09 \\
\hline 960 & & 2.5 & 0.98 & 4.15 & 1.25 & 1.26 \\
\hline 22 & \multirow{6}{*}{$200 \times 200 \times 4$} & 120.7 & 2.31 & 4.96 & 1.10 & 1.07 \\
\hline 180 & & 101.2 & 1.93 & 4.90 & 1.10 & 1.07 \\
\hline 450 & & 90.5 & 1.73 & 5.23 & 1.13 & 1.10 \\
\hline 550 & & 86.3 & 1.65 & 5.17 & 1.15 & 1.12 \\
\hline 760 & & 41.7 & 0.98 & 4.50 & 1.07 & 1.04 \\
\hline 960 & & 4.3 & 0.84 & 4.07 & 1.24 & 1.21 \\
\hline 22 & \multirow{6}{*}{$200 \times 200 \times 8$} & 501.7 & 2.14 & 5.30 & 1.25 & 1.16 \\
\hline 180 & & 421.2 & 1.79 & 5.24 & 1.26 & 1.16 \\
\hline 450 & & 375.0 & 1.60 & 5.57 & 1.28 & 1.19 \\
\hline 550 & & 356.0 & 1.52 & 5.48 & 1.30 & 1.20 \\
\hline 760 & & 178.9 & 0.94 & 4.97 & 1.26 & 1.16 \\
\hline 960 & & 17.8 & 0.78 & 4.33 & 1.41 & 1.30 \\
\hline 22 & \multirow{6}{*}{$200 \times 200 \times 12$} & 1056.6 & 2.11 & 5.03 & 1.24 & 1.13 \\
\hline 180 & & 882.9 & 1.76 & 4.95 & 1.24 & 1.13 \\
\hline 450 & & 795.7 & 1.59 & 5.32 & 1.28 & 1.17 \\
\hline 550 & & 758.6 & 1.52 & 5.26 & 1.30 & 1.19 \\
\hline 760 & & 353.5 & 0.87 & 4.42 & 1.17 & 1.07 \\
\hline \multirow[t]{7}{*}{960} & & 34.9 & 0.71 & 3.82 & 1.30 & 1.19 \\
\hline & & Mean, $P_{m}$ & 1.57 & 4.76 & 1.16 & 1.13 \\
\hline & & $\mathrm{COV}, V_{p}$ & 0.334 & 0.102 & 0.111 & 0.071 \\
\hline & \multicolumn{2}{|c|}{ Reliability index, $\beta_{1}$} & 3.12 & 8.16 & 3.33 & 4.00 \\
\hline & \multicolumn{2}{|c|}{ Resistance factor, $\phi_{w 1}$} & 0.70 & 0.91 & 0.80 & 0.70 \\
\hline & \multirow{2}{*}{\multicolumn{2}{|c|}{$\begin{array}{l}\text { Reliability index, } \beta_{2} \\
\text { Resistance factor, } \phi_{w 2}\end{array}$}} & 3.12 & 9.17 & 3.84 & 4.00 \\
\hline & & & 0.70 & 0.70 & 0.70 & 0.70 \\
\hline
\end{tabular}

Table 5. Comparison of Web Crippling Strengths Predicted from Finite Element Analysis with Design Strengths for EOF loading condition 


\begin{tabular}{|c|c|c|c|c|c|c|}
\hline \multirow{4}{*}{$\mathrm{T}$} & \multirow{5}{*}{ Section } & \multirow{2}{*}{$\begin{array}{c}\text { FEA } \\
\text { IOF }\end{array}$} & \multicolumn{4}{|c|}{ Comparison } \\
\hline & & & ASCE & EC3 & NAS & Proposed \\
\hline & & \multirow{2}{*}{$P_{\text {FEA }}$} & $P_{F E A}$ & $\underline{P_{F E A}}$ & $\underline{P_{F E A}}$ & $\underline{P_{F E A}}$ \\
\hline & & & $\overline{P_{A S C E}}$ & $\overline{P_{E C 3}}$ & $\overline{P_{N A S}}$ & $\overline{P_{p}}$ \\
\hline$\left({ }^{\circ} \mathrm{C}\right)$ & & $(\mathrm{kN})$ & & & & \\
\hline 22 & \multirow{6}{*}{$200 \times 200 \times 2$} & 50.4 & 1.69 & 1.71 & 1.32 & 1.02 \\
\hline 180 & & 42.8 & 1.43 & 1.71 & 1.35 & 1.04 \\
\hline 450 & & 38.1 & 1.31 & 1.81 & 1.37 & 1.06 \\
\hline 550 & & 36.4 & 1.27 & 1.80 & 1.40 & 1.08 \\
\hline 760 & & 18.0 & 0.92 & 1.60 & 1.33 & 1.03 \\
\hline 960 & & 2.0 & 0.94 & 1.56 & 1.67 & 1.28 \\
\hline 22 & \multirow{6}{*}{$200 \times 200 \times 3$} & 108.3 & 1.65 & 1.78 & 1.12 & 1.00 \\
\hline 180 & & 90.5 & 1.38 & 1.75 & 1.12 & 1.00 \\
\hline 450 & & 80.6 & 1.26 & 1.86 & 1.15 & 1.02 \\
\hline 550 & & 77.1 & 1.23 & 1.84 & 1.17 & 1.04 \\
\hline 760 & & 37.6 & 0.88 & 1.62 & 1.10 & 0.98 \\
\hline 960 & & 3.9 & 0.83 & 1.47 & 1.28 & 1.15 \\
\hline 22 & \multirow{6}{*}{$200 \times 200 \times 4$} & 186.9 & 1.61 & 1.84 & 1.04 & 1.01 \\
\hline 180 & & 156.5 & 1.35 & 1.81 & 1.04 & 1.01 \\
\hline 450 & & 141.2 & 1.25 & 1.95 & 1.08 & 1.05 \\
\hline 550 & & 134.8 & 1.21 & 1.93 & 1.10 & 1.06 \\
\hline 760 & & 58.4 & 0.77 & 1.51 & 0.92 & 0.89 \\
\hline 960 & & 6.5 & 0.78 & 1.47 & 1.15 & 1.11 \\
\hline 22 & \multirow{6}{*}{$200 \times 200 \times 8$} & 698.0 & 1.52 & 1.99 & 0.92 & 1.05 \\
\hline 180 & & 584.9 & 1.28 & 1.97 & 0.92 & 1.06 \\
\hline 450 & & 526.2 & 1.18 & 2.11 & 0.95 & 1.09 \\
\hline 550 & & 501.0 & 1.14 & 2.08 & 0.97 & 1.11 \\
\hline 760 & & 241.4 & 0.81 & 1.81 & 0.90 & 1.03 \\
\hline 960 & & 24.4 & 0.74 & 1.60 & 1.02 & 1.17 \\
\hline 22 & \multirow{6}{*}{$200 \times 200 \times 12$} & 1563.4 & 1.58 & 2.15 & 0.90 & 1.12 \\
\hline 180 & & 1318.9 & 1.33 & 2.14 & 0.91 & 1.13 \\
\hline 450 & & 1195.9 & 1.24 & 2.31 & 0.95 & 1.18 \\
\hline 550 & & 1135.8 & 1.20 & 2.28 & 0.96 & 1.19 \\
\hline 760 & & 527.9 & 0.82 & 1.91 & 0.86 & 1.07 \\
\hline \multirow[t]{7}{*}{960} & & 52.3 & 0.74 & 1.66 & 0.96 & 1.19 \\
\hline & & Mean, $P_{m}$ & 1.18 & 1.83 & 1.10 & 1.07 \\
\hline & & $\mathrm{COV}, V_{p}$ & 0.247 & 0.124 & 0.176 & 0.074 \\
\hline & \multicolumn{2}{|c|}{ Reliability index, $\beta_{1}$} & 2.94 & 4.34 & 2.37 & 3.77 \\
\hline & \multicolumn{2}{|c|}{ Resistance factor, $\phi_{w 1}$} & 0.70 & 0.91 & 0.90 & 0.70 \\
\hline & \multicolumn{2}{|c|}{ Reliability index, $\beta_{2}$} & 2.94 & 5.30 & 3.20 & 3.77 \\
\hline & \multicolumn{2}{|c|}{ Resistance factor, $\phi_{w 2}$} & 0.70 & 0.70 & 0.70 & 0.70 \\
\hline
\end{tabular}

Table 6. Comparison of Web Crippling Strengths Predicted from Finite Element Analysis with Design Strengths for IOF loading condition 


\begin{tabular}{|c|c|c|c|c|c|c|}
\hline \multirow{4}{*}{$\mathrm{T}$} & \multirow{5}{*}{ Section } & \multirow{2}{*}{$\begin{array}{c}\text { FEA } \\
\text { ETF }\end{array}$} & \multicolumn{4}{|c|}{ Comparison } \\
\hline & & & ASCE & EC3 & NAS & Proposed \\
\hline & & \multirow{2}{*}{$P_{F E A}$} & $P_{F E A}$ & $\underline{P_{F E A}}$ & $\underline{P_{F E A}}$ & $\underline{P_{F E A}}$ \\
\hline & & & $\overline{P_{A S C E}}$ & $\overline{P_{E C 3}}$ & $\overline{P_{N A S}}$ & $\overline{P_{p}}$ \\
\hline$\left({ }^{\circ} \mathrm{C}\right)$ & & $(\mathrm{kN})$ & & & & \\
\hline 22 & \multirow{6}{*}{$200 \times 200 \times 2$} & 18.6 & 2.36 & 2.98 & 2.09 & 1.23 \\
\hline 180 & & 15.6 & 1.98 & 2.95 & 2.10 & 1.24 \\
\hline 450 & & 13.8 & 1.75 & 3.11 & 2.13 & 1.26 \\
\hline 550 & & 13.1 & 1.66 & 3.06 & 2.15 & 1.27 \\
\hline 760 & & 6.6 & 1.03 & 2.78 & 2.09 & 1.24 \\
\hline 960 & & 0.7 & 0.91 & 2.58 & 2.49 & 1.48 \\
\hline 22 & \multirow{6}{*}{$200 \times 200 \times 3$} & 48.4 & 2.59 & 3.50 & 1.44 & 1.14 \\
\hline 180 & & 40.6 & 2.17 & 3.45 & 1.45 & 1.14 \\
\hline 450 & & 36.0 & 1.93 & 3.65 & 1.47 & 1.16 \\
\hline 550 & & 34.3 & 1.84 & 3.61 & 1.49 & 1.18 \\
\hline 760 & & 17.4 & 1.15 & 3.30 & 1.46 & 1.15 \\
\hline 960 & & 1.8 & 0.99 & 2.99 & 1.70 & 1.34 \\
\hline 22 & \multirow{6}{*}{$200 \times 200 \times 4$} & 88.3 & 2.35 & 3.63 & 1.18 & 1.09 \\
\hline 180 & & 74.0 & 1.97 & 3.58 & 1.18 & 1.09 \\
\hline 450 & & 65.4 & 1.74 & 3.78 & 1.20 & 1.11 \\
\hline 550 & & 62.2 & 1.65 & 3.72 & 1.21 & 1.12 \\
\hline 760 & & 33.1 & 1.09 & 3.57 & 1.25 & 1.15 \\
\hline 960 & & 3.4 & 0.93 & 3.22 & 1.44 & 1.33 \\
\hline 22 & \multirow{6}{*}{$200 \times 200 \times 8$} & 420.8 & 2.46 & 4.45 & 1.00 & 1.26 \\
\hline 180 & & 351.8 & 2.06 & 4.38 & 1.00 & 1.26 \\
\hline 450 & & 311.7 & 1.82 & 4.63 & 1.01 & 1.28 \\
\hline 550 & & 296.7 & 1.73 & 4.57 & 1.03 & 1.30 \\
\hline 760 & & 150.2 & 1.08 & 4.17 & 1.00 & 1.27 \\
\hline 960 & & 15.1 & 0.90 & 3.67 & 1.14 & 1.44 \\
\hline 22 & \multirow{6}{*}{$200 \times 200 \times 12$} & 993.0 & 2.71 & 4.72 & 0.91 & 1.35 \\
\hline 180 & & 829.8 & 2.27 & 4.65 & 0.92 & 1.35 \\
\hline 450 & & 742.8 & 2.03 & 4.97 & 0.94 & 1.39 \\
\hline 550 & & 707.5 & 1.93 & 4.91 & 0.95 & 1.41 \\
\hline 760 & & 339.0 & 1.14 & 4.24 & 0.88 & 1.30 \\
\hline \multirow[t]{7}{*}{960} & & 33.7 & 0.94 & 3.69 & 0.99 & 1.45 \\
\hline & & Mean, $P_{m}$ & 1.71 & 3.75 & 1.38 & 1.26 \\
\hline & & $\mathrm{COV}, V_{p}$ & 0.328 & 0.179 & 0.335 & 0.087 \\
\hline & \multicolumn{2}{|c|}{ Reliability index, $\beta_{1}$} & 3.35 & 6.24 & 2.21 & 4.32 \\
\hline & \multicolumn{2}{|c|}{ Resistance factor, $\phi_{w 1}$} & 0.70 & 0.91 & 0.90 & 0.70 \\
\hline & \multicolumn{2}{|c|}{ Reliability index, $\beta_{2}$} & 3.35 & 7.10 & 2.80 & 4.32 \\
\hline & \multicolumn{2}{|c|}{ Resistance factor, $\phi_{w 2}$} & 0.70 & 0.70 & 0.70 & 0.70 \\
\hline
\end{tabular}

Table 7. Comparison of Web Crippling Strengths Predicted from Finite Element Analysis with Design Strengths for ETF loading condition 


\begin{tabular}{|c|c|c|c|c|c|c|}
\hline \multirow{4}{*}{$\mathrm{T}$} & \multirow{5}{*}{ Section } & \multirow{2}{*}{$\begin{array}{c}\text { FEA } \\
\text { ITF }\end{array}$} & \multicolumn{4}{|c|}{ Comparison } \\
\hline & & & ASCE & EC3 & NAS & Proposed \\
\hline & & \multirow{2}{*}{$P_{\text {FEA }}$} & $P_{F E A}$ & $\underline{P_{F E A}}$ & $\underline{P_{F E A}}$ & $\underline{P_{F E A}}$ \\
\hline & & & $\overline{P_{A S C E}}$ & $\overline{P_{E C 3}}$ & $\overline{P_{N A S}}$ & $\overline{P_{p}}$ \\
\hline$\left({ }^{\circ} \mathrm{C}\right)$ & & $(\mathrm{kN})$ & & & & \\
\hline 22 & \multirow{6}{*}{$200 \times 200 \times 2$} & 33.0 & 1.51 & 5.29 & -0.86 & 1.01 \\
\hline 180 & & 27.7 & 1.27 & 5.23 & -0.87 & 1.02 \\
\hline 450 & & 24.4 & 1.14 & 5.49 & -0.88 & 1.03 \\
\hline 550 & & 23.2 & 1.11 & 5.42 & -0.89 & 1.04 \\
\hline 760 & & 12.7 & 0.89 & 5.35 & -0.94 & 1.10 \\
\hline 960 & & 1.3 & 0.83 & 4.80 & -1.08 & 1.27 \\
\hline 22 & \multirow{6}{*}{$200 \times 200 \times 3$} & 81.7 & 1.32 & 5.90 & 8.63 & 0.95 \\
\hline 180 & & 68.5 & 1.11 & 5.83 & 8.67 & 0.96 \\
\hline 450 & & 60.5 & 1.00 & 6.14 & 8.78 & 0.97 \\
\hline 550 & & 57.5 & 0.97 & 6.05 & 8.89 & 0.98 \\
\hline 760 & & 30.4 & 0.75 & 5.77 & 9.06 & 1.00 \\
\hline 960 & & 3.1 & 0.70 & 5.15 & 10.40 & 1.15 \\
\hline 22 & \multirow{6}{*}{$200 \times 200 \times 4$} & 150.2 & 1.24 & 6.17 & 1.47 & 0.94 \\
\hline 180 & & 126.0 & 1.04 & 6.10 & 1.48 & 0.94 \\
\hline 450 & & 111.5 & 0.94 & 6.44 & 1.50 & 0.96 \\
\hline 550 & & 106.1 & 0.91 & 6.35 & 1.52 & 0.97 \\
\hline 760 & & 52.6 & 0.66 & 5.68 & 1.45 & 0.93 \\
\hline 960 & & 5.4 & 0.62 & 5.11 & 1.68 & 1.07 \\
\hline 22 & \multirow{6}{*}{$200 \times 200 \times 8$} & 590.9 & 1.06 & 6.24 & 0.63 & 0.90 \\
\hline 180 & & 494.2 & 0.89 & 6.15 & 0.63 & 0.90 \\
\hline 450 & & 439.5 & 0.81 & 6.53 & 0.64 & 0.92 \\
\hline 550 & & 418.3 & 0.79 & 6.44 & 0.65 & 0.93 \\
\hline 760 & & 210.3 & 0.58 & 5.84 & 0.63 & 0.90 \\
\hline 960 & & 21.2 & 0.53 & 5.16 & 0.72 & 1.02 \\
\hline 22 & \multirow{6}{*}{$200 \times 200 \times 12$} & 1346.8 & 1.06 & 6.41 & 0.52 & 0.92 \\
\hline 180 & & 1126.4 & 0.89 & 6.32 & 0.53 & 0.92 \\
\hline 450 & & 1010.7 & 0.82 & 6.76 & 0.54 & 0.95 \\
\hline 550 & & 962.9 & 0.79 & 6.68 & 0.55 & 0.96 \\
\hline 760 & & 464.3 & 0.56 & 5.80 & 0.51 & 0.89 \\
\hline \multirow[t]{7}{*}{960} & & 46.3 & 0.51 & 5.07 & 0.57 & 1.00 \\
\hline & & Mean, $P_{m}$ & 0.91 & 5.86 & $\ldots$ & 0.98 \\
\hline & & $\mathrm{COV}, V_{p}$ & 0.271 & 0.093 & $\ldots$ & 0.084 \\
\hline & \multicolumn{2}{|c|}{ Reliability index, $\beta_{1}$} & 2.09 & 9.10 & $\ldots$ & 3.37 \\
\hline & \multicolumn{2}{|c|}{ Resistance factor, $\phi_{w 1}$} & 0.70 & 0.91 & 0.80 & 0.70 \\
\hline & \multicolumn{2}{|c|}{ Reliability index, $\beta_{2}$} & 2.09 & 10.11 & $\ldots$ & 3.37 \\
\hline & \multicolumn{2}{|c|}{ Resistance factor, $\phi_{w 2}$} & 0.70 & 0.70 & 0.70 & 0.70 \\
\hline
\end{tabular}

Table 8. Comparison of Web Crippling Strengths Predicted from Finite Element Analysis with Design Strengths for ITF loading condition 


\begin{tabular}{|c|c|c|c|c|c|c|c|c|}
\hline \multirow{2}{*}{\multicolumn{2}{|c|}{$\begin{array}{l}\text { Support and Flange } \\
\text { Conditions }\end{array}$}} & \multirow{2}{*}{ Load Cases } & \multirow{2}{*}{ C } & \multirow{2}{*}{$C_{R}$} & \multirow{2}{*}{$C_{N}$} & \multirow{2}{*}{$C_{h}$} & \multirow{2}{*}{$\begin{array}{c}\text { LRFD } \\
\phi_{w}\end{array}$} & Limits \\
\hline & & & & & & & & Туре \\
\hline \multirow{4}{*}{ Unfastened } & \multirow{4}{*}{$\begin{array}{c}\text { Stiffened } \\
\text { or Partially } \\
\text { Stiffened } \\
\text { Flange }\end{array}$} & $\begin{array}{l}\text { End One Flange } \\
\text { (EOF) }\end{array}$ & 4.0 & 0.24 & 0.41 & 0.02 & 0.70 & \multirow{4}{*}{ Duplex } \\
\hline & & $\begin{array}{l}\text { Interior One Flange } \\
\text { (IOF) }\end{array}$ & 6.0 & 0.17 & 0.37 & 0.02 & 0.70 & \\
\hline & & $\begin{array}{l}\text { End Two Flange } \\
\text { (ETF) }\end{array}$ & 3.0 & 0.30 & 0.48 & 0.03 & 0.70 & \\
\hline & & $\begin{array}{l}\text { Interior Two Flange } \\
\text { (ITF) }\end{array}$ & 8.2 & 0.27 & 0.27 & 0.001 & 0.70 & \\
\hline
\end{tabular}

Notes: The above coefficients apply when $h / t \leq 87, N / t \leq 100, N / h \leq 1.6, r_{i} / t \leq 5.5$ and $\theta=90^{\circ}$.

Table 9. Proposed Web Crippling Design Rules for Cold-Formed Stainless Steel Hollow Sections under High Temperature Conditions 


\begin{tabular}{|c|c|c|c|c|c|c|c|c|}
\hline \multirow{3}{*}{ Section } & \multicolumn{5}{|c|}{ Measured } & \multirow{2}{*}{$\begin{array}{c}\text { Test } \\
\text { EOF } \\
\text { (From Ref. [13] ) }\end{array}$} & \multirow{2}{*}{$\begin{array}{c}\text { Design } \\
\text { Proposed }\end{array}$} & \multirow{3}{*}{$\begin{array}{c}\text { Comparison } \\
\text { Proposed } \\
\frac{P_{E x p}}{P_{p}}\end{array}$} \\
\hline & \multirow{2}{*}{$\begin{array}{c}\text { Bearing } \\
\text { Length } \\
\qquad \\
\\
\text { (mm) }\end{array}$} & \multirow[b]{2}{*}{$h / t$} & \multicolumn{2}{|c|}{ Ratio } & \multirow[b]{2}{*}{$N / h$} & & & \\
\hline & & & $r_{i} / t$ & $N / t$ & & $\begin{array}{l}P_{\text {Exp }} \\
(\mathrm{kN})\end{array}$ & $\begin{array}{l}P_{p} \\
(\mathrm{kN})\end{array}$ & \\
\hline $40 \times 40 \times 2$ & 50 & 16.5 & 1.0 & 25.6 & 1.6 & $22.3^{\mathrm{a}}$ & 25.1 & $(0.89)$ \\
\hline $40 \times 40 \times 2$ & 25 & 16.7 & 1.0 & 12.9 & 0.8 & 24.7 & 19.8 & 1.25 \\
\hline $50 \times 50 \times 1.5$ & 50 & 28.7 & 1.0 & 32.4 & 1.1 & $19.8^{\mathrm{a}}$ & 15.1 & (1.31) \\
\hline $50 \times 50 \times 1.5$ & 25 & 28.7 & 1.0 & 16.2 & 0.6 & 15.5 & 11.9 & 1.30 \\
\hline $150 \times 150 \times 3$ & 150 & 48.6 & 1.7 & 53.6 & 1.1 & 47.2 & 38.5 & 1.22 \\
\hline $150 \times 150 \times 3$ & 75 & 48.7 & 1.7 & 26.9 & 0.6 & 28.8 & 30.0 & 0.96 \\
\hline $150 \times 150 \times 6$ & 150 & 21.6 & 1.0 & 25.6 & 1.2 & $184.6^{\mathrm{a}}$ & 159.1 & (1.16) \\
\hline $150 \times 150 \times 6$ & 75 & 22.2 & 1.0 & 13.1 & 0.6 & 124.3 & 122.3 & 1.02 \\
\hline $140 \times 80 \times 3$ & 75 & 39.4 & 2.1 & 24.4 & 0.6 & 37.6 & 36.3 & 1.04 \\
\hline $140 \times 80 \times 3$ & 50 & 39.3 & 2.1 & 16.2 & 0.4 & 33.6 & 31.9 & 1.05 \\
\hline $160 \times 80 \times 3$ & 75 & 49.6 & 2.1 & 26.0 & 0.5 & 32.4 & 36.1 & 0.90 \\
\hline $160 \times 80 \times 3$ & 50 & 49.6 & 2.1 & 17.3 & 0.3 & 29.6 & 31.6 & 0.94 \\
\hline $200 \times 110 \times 4$ & 100 & 45.1 & 2.1 & 25.1 & 0.6 & 60.2 & 63.2 & 0.95 \\
\hline \multirow[t]{5}{*}{$200 \times 110 \times 4$} & 50 & 44.2 & 2.1 & 12.6 & 0.3 & 40.1 & 50.8 & 0.79 \\
\hline & & & & & & & Mean, $P_{m}$ & 1.04 \\
\hline & & & & & & \multirow{2}{*}{\multicolumn{2}{|c|}{$\begin{array}{r}\mathrm{COV}, V_{p} \\
\text { Reliability index, } \beta\end{array}$}} & 0.154 \\
\hline & & & & & & & & 3.05 \\
\hline & & & & & & \multicolumn{2}{|c|}{ Resistance factor, $\phi_{w}$} & 0.70 \\
\hline
\end{tabular}

Note: ${ }^{a}$ Shear failure

Table 10. Comparison of Web Crippling Test Strengths with Design Strengths for EOF Loading Condition at Room Temperature 


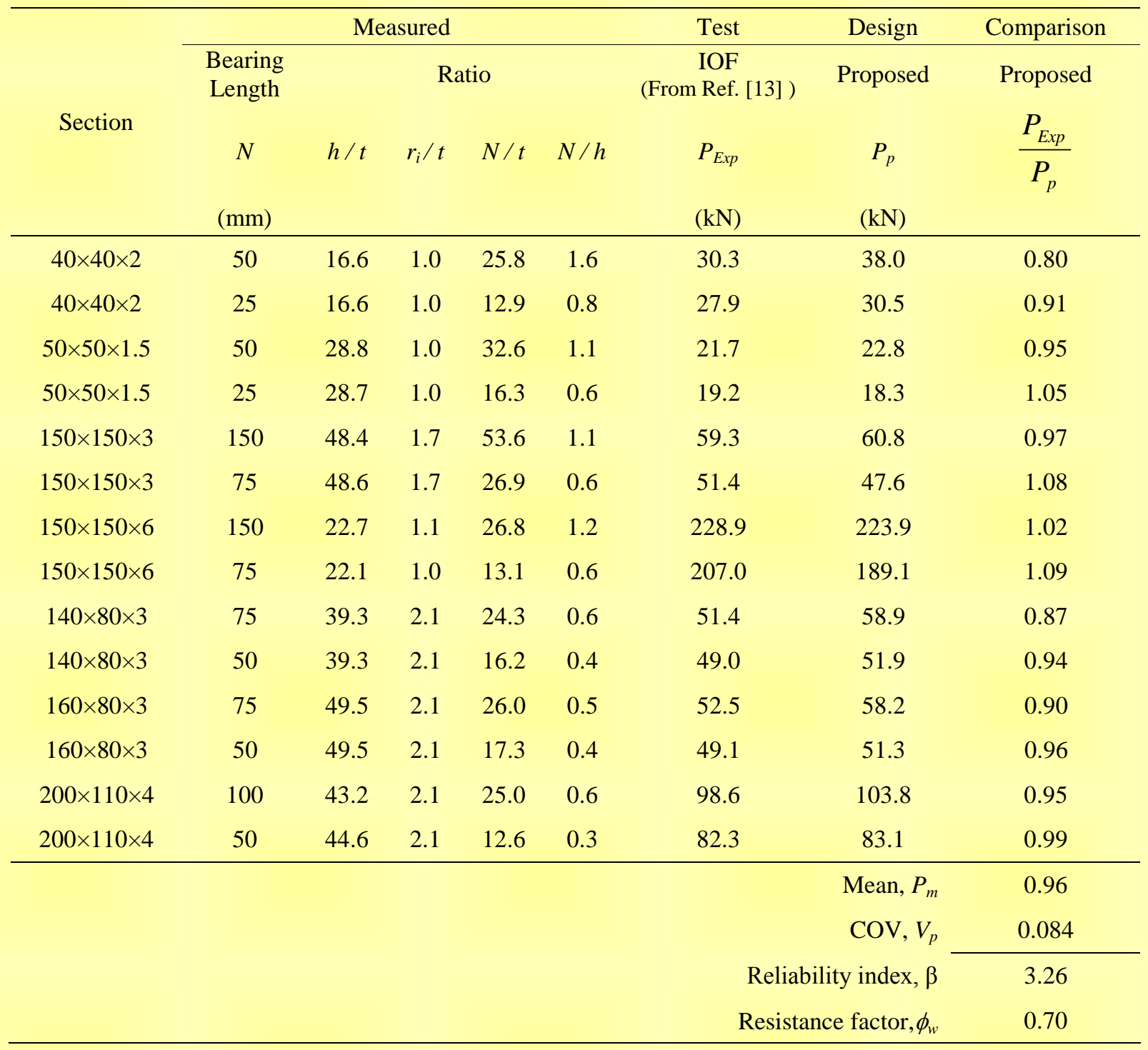

Table 11. Comparison of Web Crippling Test Strengths with Design Strengths for IOF Loading Condition at Room Temperature 


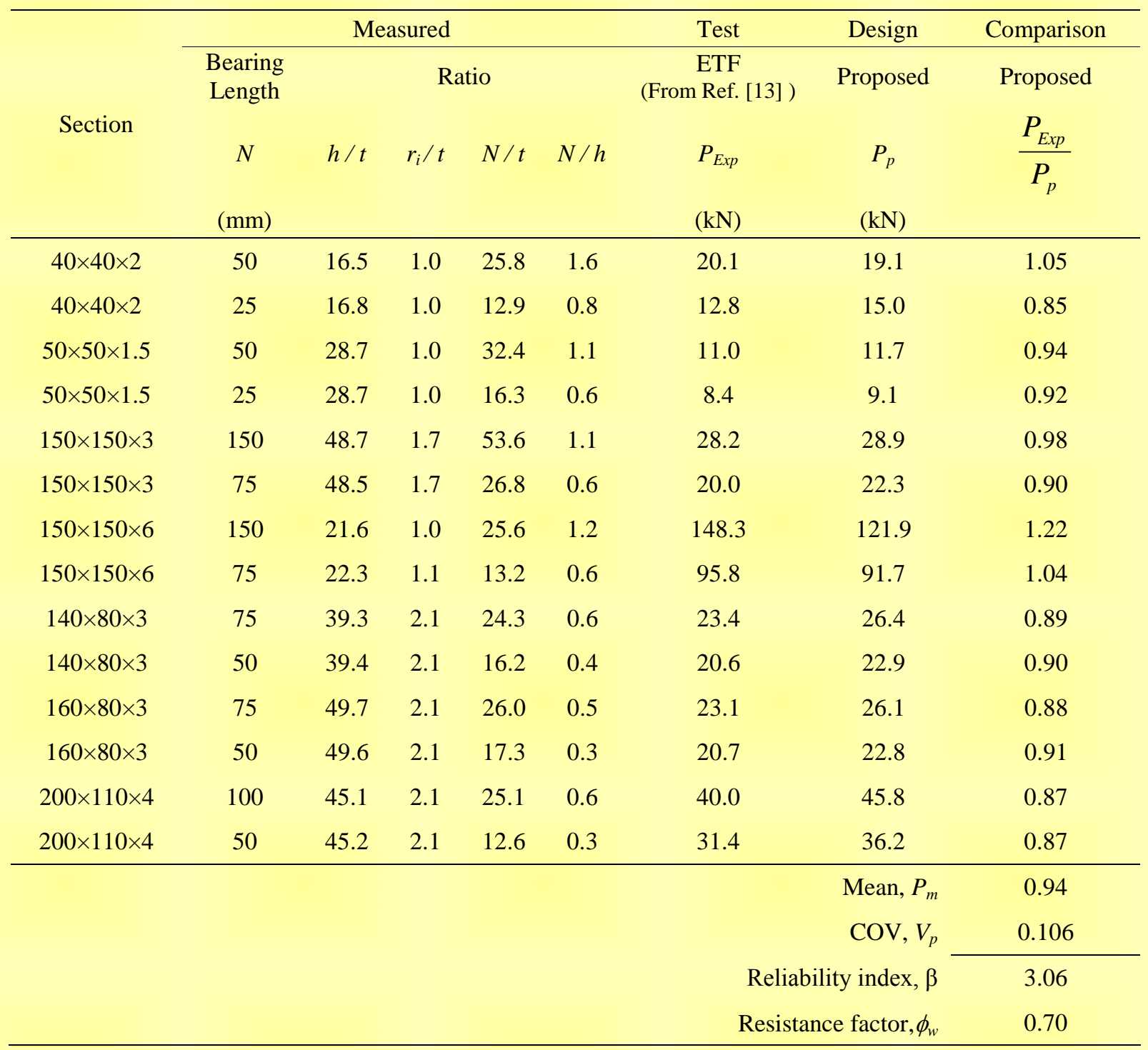

Table 12. Comparison of Web Crippling Test Strengths with Design Strengths for ETF Loading Condition at Room Temperature 


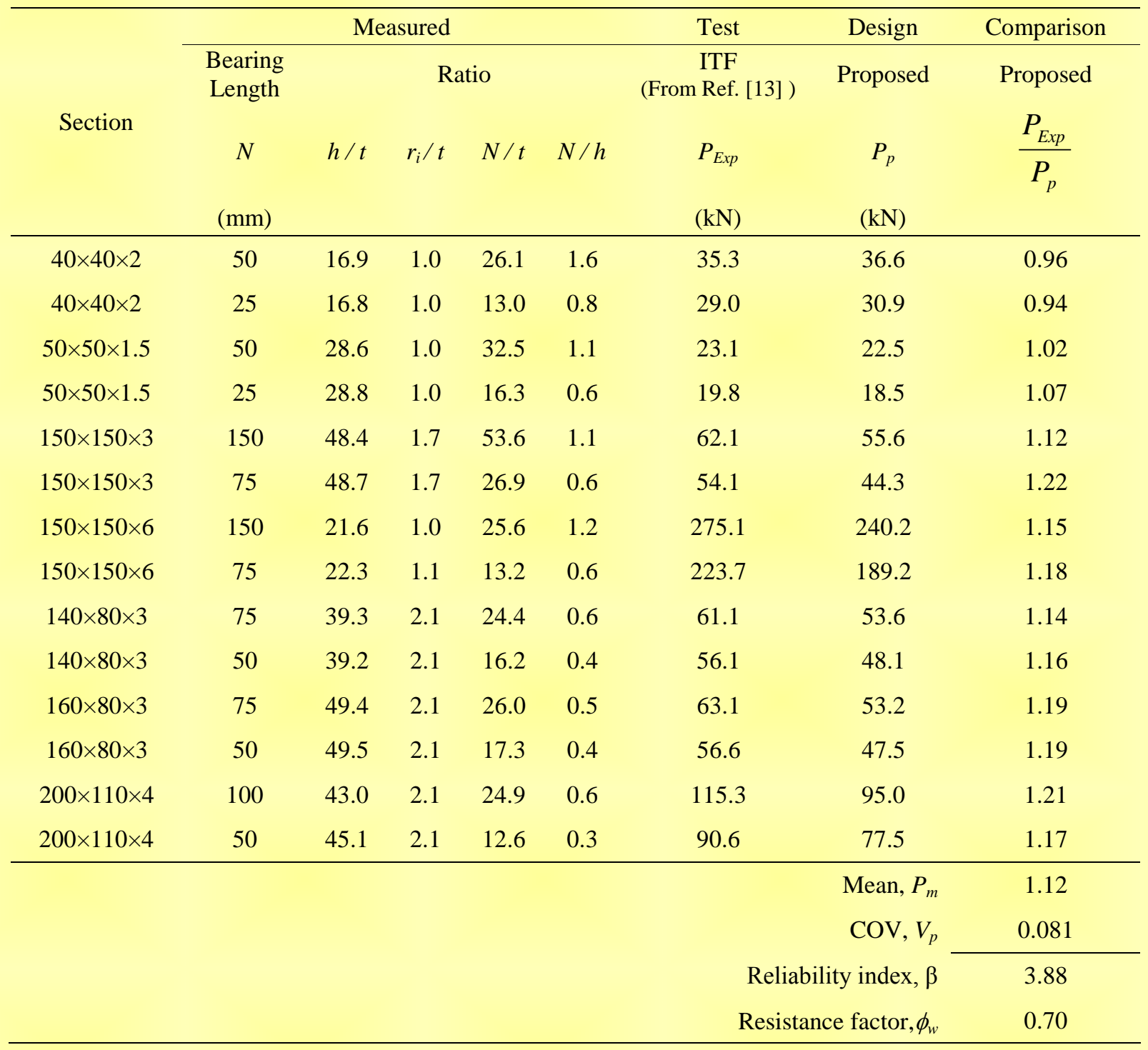

Table 13. Comparison of Web Crippling Test Strengths with Design Strengths for ITF Loading Condition at Room Temperature 